4. HISTORIA DEL DERECHO CANÓNICO 

Revista de Estudios Histórico-Jurídicos [Sección Historia del Derecho Canónico] XXXI (Valparaíso, Chile, 2009) [pp. 279 - 313]

\title{
LAS OBSERVACIONES DE LOS OBISPOS CHILENOS A LOS PROYECTOS DE LIBRO I: "NORMAE GENERALES" Y LIBRO II: "DE PERSONIS", DEL "CÓDIGO DE DERECHO CANÓNICO" DE 1917
}

["Remarks of Chilean Bishops on the Drafts of Book I: "Normae Generales" And Book Ii: "De Personis," of the Canon Law Code of 1917"]

\author{
Carlos Salinas Araneda* \\ Pontificia Universidad Católica de Valparaíso**
}

\begin{abstract}
RESUMEN
La redacción del primer Código de Derecho Canónico que tuvo la Iglesia latina fue ordenada por el papa san Pío X en 1904. La tarea codificadora, empero, no fue obra de un grupo cerrado de expertos, sino que tuvo en cuenta el parecer del episcopado, el que fue consultado en dos momentos diferentes; en ambos fueron consultados los obispos chilenos. En este trabajo se estudia, a partir de la documentación guardada en el Archivo Secreto Vaticano, las observaciones de los obispos chilenos a los proyectos de libros I y II del código que les fueran enviados en 1912.

Palabras clave: Codificación canónica - Proyectos de Código de Derecho Canónico de 1917 - Obispos chilenos Animadversiones episcoporum.
\end{abstract}

\begin{abstract}
In 1904, Pope Pious X ordered the preparation of the first Code of Canon Law of the Latin Church. This task, however, was not entrusted to a select group of experts; instead, it included the Episcopate's opinion, that was sought for in two different times. In both instances Chilean bishops were consulted. This work, based on the Vatican Secret Archives, studies the remarks made by the Chilean bishops on the drafts of books I and II of the code, sent to them in 1912.

KeYWORDS: Canon codification - Drafts of Code of Canon Law of 1917 - Chilean bishops - Animadversiones episcoporum.
\end{abstract}

* Profesor titular en la Facultad de Derecho de la Pontificia Universidad Católica de Valparaíso. Dirección del autor: Facultad de Derecho, Pontificia Universidad Católica de Valparaíso, Avenida Brasil 2950, Valparaíso, Chile. Correo electrónico: csalinas@ucv.cl. Este trabajo forma parte del proyecto de investigación FONDECYT 1070434 del que el autor es investigador responsable.

** Abreviaturas: $A$ AS. $=$ Acta Apostolicae Sedis (Ciudad del Vaticano); ASS. = Acta Sanctae Sedis $($ Ciudad del Vaticano); ASV. $=$ Archivo Secreto Vaticano; BEAS. $=$ Boletín eclesiástico del arzobispado de Santiago; CIC 1917 = Código de Derecho Canónico de 1917; CIC 1983 = Código de Derecho Canónico de 1983. 


\section{LOS PROYECTOS DE "CODEX IURIS CANONICI”}

La tarea de elaborar un Codex Iuris Canonici que sustituyera al Corpus fue iniciada por el papa san Pío X (1903-1914) a poco de haber iniciado su pontificado en los albores del siglo XX ${ }^{1}$. Lo hizo mediante el motu proprio Arduum sane munus, de 19 de marzo de $1904^{2}$, mediante el cual creó una comisión pontificia encargada de asumir la codificación del derecho de la Iglesia ${ }^{3}$. La elaboración del código, sin embargo, no fue una tarea de un grupo cerrado de iniciados, sino que, contando con el trabajo de un número importante de expertos bajo la dirección de Pedro Gasparrí ${ }^{4}$, el mismo motu proprio dispuso la intervención de todo el episcopado latino 5 . De esta manera, una de las principales características del proceso de codificación del derecho canónico de 1917 consistió en la participación, promovida por la misma Santa Sede, del episcopado en la elaboración del Codex. Dicha participación, por cierto, la primera realizada históricamente por la Iglesia al emprender la tarea de elaborar un cuerpo legislativo universal, se articuló en dos grandes momentos: el primero, al inicio de los trabajos de codificación, a través de los Postulata episcoporum; el segundo, en pleno proceso codificador, cuando se estaba llegando a la fase conclusiva del mismo, a través de las Animadversiones episcoporum. De ambos momentos es el segundo el que ahora me interesa.

Una vez que se recibieron en Roma las respuestas de los obispos a la primera consulta que se les había formulado ${ }^{6}$, las que se habían recogido en un libro re-

${ }^{1}$ Una síntesis de la historia de la codificación del derecho canónico de 1917 en SALINAS Araneda, Carlos, La codificación del derecho canónico de 1917, en Revista de Derecho de la Pontificia Universidad Católica de Valparaíso 30 (1 ${ }^{\text {er }}$ semestre 2008), pp. 311-356, con bibliografía. Recientemente, FANTAPPIE, Carlo, Chiesa romana e modernità giuridica. L'edificazione del sistema canonistico (1563-1903) con biblografía actualizada (Milano, Giuffrè, 2008), dos tomos.

${ }^{2}$ Publicado en ASS. 36 (1903-1904), pp. 549-551. El m.p. lleva la fecha 14 de abril de 1904, pero parece que se trata de un error de imprenta, pues en la carta circular Pergratum mibi, fechada el 25 de marzo de 1904, hay una referencia expresa al m.p. Arduum sane munus. Son de esta opinión, Llobell, Joaquín - De León, Enrique - NaVarrete, Jesús, Il libro "De processibus" nella codificazione del 1917. Studi e documenti (Milano, Giuffré, 1999), I, p. 34 n. 30. Sobre los inicios de la codificación piobenedictina puede verse FanTAPPİ, Carlo, Gl'inizi della codificazione pio-benedettina, en Il diritto ecclesiastico 113 (2002), pp. 16-83. Del mismo autor puede verse su libro más reciente Chiesa romana e modernità giuridica. L'edificazione del sistema canonistico (1563-1903) (Milano, Giuffrè, 2008) 2 tomos, con bibliografía actualizada.

${ }^{3}$ La nómina de sus integrantes en ASS. 36 (1903-1904), p. 551.

${ }^{4}$ Antiguo profesor en el Instituto católico de Paris, entonces arzobispo titular de Cesarea y secretario de la $\mathrm{S}$. Congregación de asuntos eclesiásticos extraordinarios, a quien se le nombró al mismo tiempo presidente de la Comisión de consultores. Posteriormente sería hecho cardenal (1907).

${ }^{5}$ En la decisión cuarta el papa manifestaba su deseo de que todo el episcopado, conformándose a las reglas que serían dadas en tiempo oportuno, colaboraran y concurrieran a esta obra tan importante: "IV. Volumus autem universum episcopatum, iuxta normas opportune tradendas, in gravissimum hoc opus conspirare atque concurrere".

${ }^{6}$ Para la respuesta de los obispos chilenos a la primera de las consultas puede verse SALINAS ARANEDA, Carlos, El primer aporte de los obispos chilenos a la codificación del derecho canónico de 1917: los "postulata episcoporum", en Revista de Estudios Histórico-Jurídicos 30 (2008), pp. 
dactado por el consultor Bernardin $\mathrm{Klumper}^{7}$, el proceso de codificación siguió su desarrollo con la preparación de proyectos parciales los que, una vez terminados, dieron origen a una nueva consulta al episcopado de todo el mundo. Dicha consulta, que se hizo entre los años 1912 y 1914, contó con la oposición de algunos cardenales $^{8}$, pero fue autorizada expresamente por san Pío X y se hizo enviando los distintos proyectos parciales a todos los obispos y prelados de la Iglesia latina que, de acuerdo con los cánones vigentes, hubiesen debido ser convocados a un eventual Concilio Ecuménico, incluidos los vicarios y prefectos apostólicos.

Por medio de una carta circular firmada por el cardenal Pedro Gasparri, presidente de la comisión codificadora, fechada el 20 de marzo de 1912, se envió a los obispos y a los superiores generales de las órdenes religiosas el proyecto de libro primero, Normae generales, y del libro segundo, De personis, recogidos los dos en un solo volumen?. Según las instrucciones que se daban a los obispos en dicha circular, podían proceder al examen de los cánones contenidos en cada uno de los dos proyectos valiéndose de tres expertos en derecho canónico, clérigos regulares o seculares, pero, tanto los obispos como los consultores quedaban obligados al secreto pontificio; las observaciones debían ser enviadas a la Santa Sede no más allá de los seis meses de haber recibido el proyecto. Un año después, el 1 de abril de 1913, se envió el Libro tercero, De rebus ${ }^{10}$, anunciándose el envío del Libro cuarto, De delictis et poenis ${ }^{11}$, y del Libro quinto, De iudicis ecclesiasticis ${ }^{12}$, que les

317-342; El MISMO, El primer aporte de los obispos chilenos a la codificación del derecho canónico de 1917: los "postulata" del obispo de Ancud, Ramón Ángel Jara Ruz, en Boletín de la Academia Chilena de la Historia 117 (2008), pp. 161-189; El MISMO, El primer aporte de los obispos chilenos a la codificación del derecho canónico de 1917: los "postulata episcoporum" acerca del matrimonio, en Historia 41 (2008) 2, pp. 413-446; El MISMO, El primer aporte de los obispos chilenos a la codificación del derecho canónico de 1917: los "postulata" del obispo de Concepción, Plácido Labarca, en Revista de Derecho de la Universidad Católica de la Santísima Concepción (2008), pp. 89-105.; El mismo, Un manuscrito inédito del obispo chileno Rafael Fernández Concha: un proyecto parcial de Código de Derecho Canónico presentado con ocasión de la codificación canónica de 1917, en Revista de Estudios Histórico-Jurídicos 29 (2007), pp. 481-514.

${ }^{7}$ Codex Iuris Canonicil Postulata Episcoporum/ in ordinem digestal a/ Rmo. P. Bernardino Klumper O. F. M./ Consultore/ Romael Typis Vaticanis/ 1905/ 283 pp. ASV. CIC 1917, caja 4.

${ }^{8}$ Entendían que el envío de los ejemplares, la espera de las respuestas de los obispos y el análisis de las mismas retrasarían la promulgación del código.

${ }^{9}$ (Schema Codicis Iuris Canonici)/(Sub secreto pontificio)/Sanctissimi Domini Nostri/ Pii PP. X/ Codex Iuris Canonicil cum notis/ Petri card. Gasparri/ [escudo pontificio de Pío X]/ Romae/ Typis polyglottis Vaticanis/MDCCCCXII/, 281 pp. El libro I lo componían 79 cánones y el II, 567 cánones. ASV. CIC 1917, caja 23.

${ }^{10}$ (Schema Codicis Iuris Canonici)/(Sub secreto pontificio)/Sanctissimi Domini Nostri/Pii PP.

X/ Codex Iuris Canonici/ cum notis/Petri card. Gasparri/ [escudo pontificio de Pío X]/ Romae/ Typis polyglottis Vaticanis/ MDCCCCXIII/ 365 pp., 831 cánones. ASV. CIC 1917, caja 51.

${ }^{11}$ (Schema Codicis Iuris Canonici)/(Sub secreto pontificio)/Sanctissimi Domini Nostri/Pii PP. X/Codex Iuris Canonici/cum notis/Petri card. Gasparri/[escudo pontificio de Pío X]/ Romae/ Typis polyglottis Vaticanis/ MDCCCCXIII/ 106 pp., 227 cánones. ASV. CIC 1917, caja 79.

${ }^{12}$ (Schema Codicis Iuris Canonici)/(Sub secreto pontificio)/Codex Iuris Canonici/cum notis/ Petri card. Gasparri/[escudo pontificio de Benedicto XV]/ Romae/ Typis polyglottis Vaticanis/ MDCCCCXIV/ 238 pp., 773 cánones. ASV. CIC 1917, caja 70. 
serían transmitidos, respectivamente, el 1 de julio de 1913 y el 15 de noviembre de $1914^{13}$. La numeración de los cánones no era única y continua para todos estos proyectos parciales, sino que se iniciaba en cada uno de los volúmenes. Y todos ellos, con excepción del quinto, llevaban, a pie de página, notas en las que se individualizaban la o las fuentes de donde había sido tomado el respectivo canon; según se indicaba en la portada de cada uno de estos volúmenes, ellas correspondían al cardenal Gasparri. La falta de notas en el último de los libros se decidió para acelerar los trabajos de impresión y distribución y no porque se considerasen poco útiles.

Las respuestas enviadas en esta oportunidad por los obispos, los ordinarios y los superiores religiosos consultados dieron origen a las Animadversiones Episcoporum u observaciones de los obispos a los diversos proyectos parciales de Código de Derecho Canónico elaborados por la comisión de codificación. Las Animadversiones, nada más llegar a Roma, eran clasificadas y ordenadas según la numeración que tenían los cánones respectivos en los proyectos. Algunas de estas observaciones fueron enviadas por los obispos individualmente, otras conjuntamente con los demás obispos de la provincia eclesiástica y su metropolitano. Y como había sucedido con los Postulata, ahora las Animadversiones fueron igualmente impresas en textos que, al igual que había sucedido la primera vez, permanecieron en estricta reserva ${ }^{14}$.

La idea de haber sometido los proyectos a las observaciones del episcopado, al final, se reveló feliz y fecunda. De hecho las diferencias entre los proyectos y el texto finalmente publicado no son de mera forma, sino que son más importantes y profundas ${ }^{15}$.

\section{LOS OBISPOS CHILENOS CONSULTADOS}

Los distintos proyectos parciales, como lo he indicado, fueron enviados a todos los obispos y prelados de la Iglesia latina que, de acuerdo con los cánones vigentes, hubiesen debido ser convocados a un eventual Concilio Ecuménico, incluidos los vicarios y prefectos apostólicos. Según Donoso ${ }^{16}$, a un concilio ecuménico o general eran convocados, primeramente, los obispos, quienes "en razón de su

${ }^{13}$ El texto de la misma en Llobell, Joaquín - De LeÓn, Enrique - Navarrete, Jesús, cit. (n. 2), I, pp. 841-842.

${ }^{14}$ Riassunto delle osservazioni dei Vescovi e Superiori Regolari al Lib. I e II del Codice, en el que, en un centenar de páginas, se hace una síntesis de las mismas; Observationes Epicoporum et Superiorum Regularium in Lib. I et II Codicis, más breve en que se recogen las observaciones llegadas con retraso a Roma. Ambos textos impresos se encuentran en la biblioteca de la Pontificia Universidad Gregoriana de Roma. Ibíd., p. 85.

${ }^{15}$ Un primer análisis en lo que se refiere al derecho matrimonial en VETUlani, A., Codex Juris Canonici, en Dictionnaire de Droit Canonique (Paris, 1942), III, col. 930-933, donde se identifica una larga y significativa lista de cánones agregados al proyecto de 1912, además de otros que fueron suprimidos.

${ }^{16}$ Donoso, Justo, Instituciones de derecho canónico americano (Valparaíso, 1848-1849), I, p. 20. 
dignidad y jurisdicción, son verdaderos jueces en las decisiones conciliares, y en calidad de tales, suscriben los decretos" 17 .

El año 1912, año en que se envió el proyecto de los libros I y II, era arzobispo de Santiago, Juan Ignacio González Eyzaguirre ${ }^{18}$; obispo de La Serena, Ramón Ángel Jara Ruz ${ }^{19}$; obispo de Concepción, Luis Enrique Izquierdo Vargas ${ }^{20}$ y Obispo de Ancud, fray Pedro Armengol Valenzuela Poblete, O. de M. ${ }^{21}$. Además, ya estaban erigidos los vicariatos apostólicos de Antofagasta ${ }^{22}$ cuyo vicario en 1912 era Luis Silva Lezaeta ${ }^{23}$; y de Tarapacá ${ }^{24}$, cuyo vicario en 1912 era José María Caro Rodríguez ${ }^{25}$. También existía la prefectura apostólica de Magallanes ${ }^{26}$,

${ }^{17}$ Eran también convocados los cardenales, aunque no fuesen obispos; los generales de las órdenes regulares y los abades que tenían territorio y jurisdicción independiente de los obispos. Junto a los anteriores, concurrían gran número de canonistas y teólogos famosos, los ministros de los soberanos católicos y alguna vez estos en persona.

${ }^{18}$ Nacido el 12 de julio de 1844, san Pío X lo había elegido obispo titular de Flaviades el 18 de abril de 1907; fue promovido al arzobispado de Santiago por el mismo san Pío X el 8 de agosto de 1908, sucediendo a Mariano Casanova que había fallecido el 16 de mayo de ese mismo año. Para las diligencias relativas a su preconización como arzobispo de Santiago, véase Retamal Fuentes, Fernando, Chilensia Pontificia. Monumenta Ecclesiae Chilensia (Santiago, Ediciones Universidad Católica de Chile, 2005), vol. II, tomo III, pp. 1122-1126.

${ }^{19}$ Nacido el 2 de agosto de 1852, León XIII lo había elegido obispo de Ancud el 2 de mayo de 1898. San Pío X lo trasladó a La Serena el 31 de agosto de 1909, sucediendo a Florencio Fontecilla Sánchez, fallecido el 1 de marzo de 1909. Acerca de su traslado al obispado de La Serena, véase la carta que le dirige san Pío X, en BEAS. 17, pp. 671-672, ahora en RETAMAL Fuentes, Fernando, cit. (n. 18), pp. 1158-1159.

${ }^{20}$ Nacido el 21 de enero de 1861, san Pío X lo eligió obispo de Concepción el 26 de enero de 1906, sucediendo a Plácido Labarca, fallecido el 9 de octubre de 1905.

${ }^{21}$ Nacido el 5 de julio de 1853, san Pío X lo eligió obispo de San Carlos de Ancud, el 30 de junio de 1910, sucediendo a Ramón Ángel Jara Ruz, trasladado al obispado de La Serena. En 1880 había sido elegido maestro general de la Orden de la Merced, la que gobernó hasta que fue elegido obispo de Ancud. El 9 de enero de 1904 el mismo papa lo había nombrado consultor para participar en la redacción del código canónico que se había empezado a preparar.

${ }^{22}$ Fue erigido por León XIII en fecha que no ha sido posible precisar. Oviedo Cavada, Carlos, Los obispos de Chile (Santiago, Editorial Andrés Bello, 1996), p. 35.

${ }^{23}$ Nacido el 2 de febrero de 1860, fue nombrado vicario apostólico de Antofagasta desde el 15 de mayo de 1887 hasta 1896; su nombramiento en Retamal Fuentes, Fernando, Chilensia Pontificia. Monumenta Ecclesiae Chilensia (Santiago, Ediciones Universidad Católica de Chile, 2002), vol. II, tomo I, pp. 430-431. Nuevamente fue vicario apostólico de Antofagasta el 4 de noviembre de 1905, cargo que desempeñó hasta ser nombrado obispo de Antofagasta. San Pío X lo eligió obispo titular de Oleno el 5 de enero de 1912; fue consagrado en la catedral de Santiago el 28 de abril de 1912. Al ser creada la diócesis de Antofagasta, Pío XI lo designó su primer obispo el 3 de febrero de 1928. Oviedo Cavada, Carlos, cit. (n. 22), pp. 217-218.

${ }^{24}$ Fue erigido durante el pontificado de León XIII en fecha que no ha sido posible precisar. Ibíd., p. 43.

${ }^{25}$ Nacido el 23 de junio de 1866, fue nombrado vicario apostólico de Tarapacá el 6 de mayo de 1911. San Pío X lo eligió obispo titular de Milas el 5 de enero de 1912; fue consagrado en la catedral de Santiago el 28 de abril de 1912 y permaneció en el vicariato hasta que Pío XI lo trasladó a diócesis de La Serena. Ibíd., pp. 88-89.

${ }^{26}$ Durante el pontificado de León XIII fue creada la prefectura apostólica de Magallanes el 16 de noviembre de 1883; véanse los decretos de erección y de nombramiento de prefecto en Retamal Fuentes, Fernando, cit. (n. 23), vol. II, tomo I, pp. 216-217. Posteriormente fue crea- 
cuyo prefecto apostólico era José Fagnano, $\mathrm{SDB}^{27}$; y la prefectura apostólica de Araucanía ${ }^{28}$.

Conforme a lo anterior, además del arzobispo y de los tres obispos diocesanos, había en Chile otros dos obispos, consagrados el mismo año 1912, si bien obispos titulares, pero a la cabeza de los dos vicariatos apostólicos existentes a ese momento, los obispos José María Caro Rodríguez y Luis Silva Lezaeta. Y los prefectos de las prefecturas apostólicas igualmente existentes en Chile. Si, conforme a la carta enviada desde Roma, las observaciones a los proyectos debían ser hechas, además del arzobispo y los obispos, por los vicarios y prefectos apostólicos, todos ellos debieron ser convocados para conocer y formular observaciones a los proyectos enviados desde la Santa Sede. Sin embargo, sólo participaron el arzobispo y sus obispos sufragáneos por lo que el informe enviado a Roma en 1912 con las observaciones a los libros I y II fue firmado sólo por el arzobispo y sus sufragáneos.

De los obispos que participaron en el informe, dos de ellos ya habían participado en el proceso de codificación que se llevaba adelante desde 1904. Uno de ellos era el actual obispo de Ancud, fray Pedro Armengol Valenzuela quien había sido incluido en la primera lista de consultores elaborada en dicho año al inicio mismo de la codificación canónica ${ }^{29}$, mientras se desempeñaba en Roma como maestro general de la Orden de la Merced. El otro era el actual obispo de La Serena, Ramón Ángel Jara, quien había participado en 1904 en el primer informe enviado a Roma, cuando entonces era obispo de Ancud, no sólo uniéndose al informe enviado por el arzobispo Mariano Casanova, sino agregando propuestas propias $^{30}$. Los otros dos prelados, el arzobispo de Santiago, Juan Ignacio González Eyzaguirre, y el obispo de Concepción, Luis Enrique Izquierdo Vargas se enfrentaban por primera vez al proceso codificador.

Sabemos que según las instrucciones que se dieron a los obispos en la circular con que se envió el proyecto de ambos libros, podían proceder al examen de los cánones contenidos en cada uno de ellos valiéndose de tres expertos en derecho canónico, clérigos regulares o seculares, pero, tanto los obispos como los consultores quedaban obligados al secreto pontificio. No hay muchos antecedentes sobre quienes pudieron haber asesorado a los obispos chilenos; parece, sin embargo, que el único que asesoró a los obispos fue el presbítero Carlos Silva Cotapos ${ }^{31}$, a la sazón

do vicariato apostólico por Benedicto XV el 4 de octubre de 1916, cuando las consultas acerca del código canónico ya habían terminado. Oviedo Cavada, Carlos, cit. (n. 22), p. 45.

${ }^{27}$ Fue su único prefecto apostólico desde el 2 de diciembre de 1883 al 18 de septiembre de 1916. Ibíd.

${ }^{28}$ La prefectura apostólica de Araucanía se inició en 1848, como una jurisdicción de los padres capuchinos, sin separar su territorio de la diócesis de Ancud ni de la de Concepción. Fue erigida por León XIII el 16 de julio de 1901 confiándola a los mismos capuchinos. Ibíd., p. 50. Retamal Fuentes, Fernando, cit. (n. 23), vol. II, tomo II, pp. 950-951.

${ }^{29}$ La nómina de los mismos, entre quienes se menciona a fray Pedro Armengol Valenzuela, fue comunicada por el Secretario de Estado, Rafael Merry del Val, a los obispos del mundo, por carta circular Pergratum mihi, de 25 de marzo de 1904. Su texto en ASS. 36 (1903-1904), pp. 603-604

${ }^{30}$ Salinas Araneda, Carlos, El primer aporte, cit. (n. 6), pp. 161-189.

${ }^{31}$ Nacido el 10 de mayo de 1868, fue ordenado sacerdote el 21 de septiembre de 1891, un 
secretario de cámara del arzobispo de Santiago, quien le había encargado "estudiar el proyecto de Código Canónico” y que en la asamblea trienal de los obispos de la provincia eclesiástica chilena celebrada en septiembre de 1912, propuso, en la sesión del 5 de septiembre de 1912, cinco indicaciones a las que me referiré más adelante $^{32}$. Estaba particularmente preparado para ello, pues no solo fue profesor de derecho canónico en el seminario de Santiago y en la Universidad Católica de Chile, sino que pocos años antes de esta consulta romana había escrito unas nociones de derecho canónico ${ }^{33}$ reeditadas poco después ${ }^{34}$, y había actualizado las Instituciones de derecho canónico americano de Justo Donoso para su nueva edición ${ }^{35}$. Además, había formado parte de la comisión nombrada por el anterior arzobispo de Santiago, Mariano Casanova ${ }^{36}$, para que, bajo la presidencia del obispo Rafael Fernández Concha, le asesorase en la redacción del primer informe que habían enviado a Roma los obispos chilenos, como respuesta a la primera consulta que se les había hecho, los postulata episcoporum ${ }^{37}$.

\section{OBSERVACIONES A LOS LIBROS I Y II}

El artículo 208 del Concilio Plenario de América Latina, utilizando palabras de León XIII ${ }^{38}$, recomendaba encarecidamente a los prelados del continente "que con frecuencia os comuniquéis vuestras opiniones y, en cuanto lo permitan las distancias y vuestros sagrados deberes, multipliquéis más y más las reuniones episcopales", para lo cual, el concilio establecía que tales reuniones no deberían pasar de tres años, fijándose en cada provincia de común acuerdo de los obispos ${ }^{39}$. Conforme

año después de haber obtenido su título de abogado en la Universidad de Chile. Era secretario desde 1902 y lo fue hasta 1914. Al año siguiente fue provisor y vicario general hasta 1918, el año en que entró en vigencia el nuevo código. Desde 1907 era canónigo de la catedral de Santiago. Benedicto XV lo eligió obispo de La Serena el 20 de febrero de 1918. Posteriormente fue el primer obispo de Talca desde 1926 a 1939. Falleció en 1941. Oviedo Cavada, Carlos, cit. (n. 22), pp. 215-216.

${ }^{32} \mathrm{El}$ acta de la asamblea trienal en lo que se refiere a los proyectos de libros I y II del Código de Derecho Canónico, en Archivo del Arzobispado de Santiago, Libro primero de actas de las sesiones celebradas por los Illmos. Señores arzobispo y obispos sufragáneos de Concepción, Serena y Ancud, pp. 37-43, publicado en Retamal Fuentes, Fernando, cit. (n. 18), vol. II, tomo III, pp. 1264-1266.

${ }^{33}$ Silva Cotapos, Carlos, Nociones de derecho canónico (Santiago, Imprenta La Revista Católica, 1907), 205 pp.

${ }^{34}$ Silva Cotapos, Carlos, Nociones de derecho canónico² (Santiago, Imprenta de San José, 1909), $211 \mathrm{pp}$.

${ }^{35}$ Donoso, Justo, Instituciones de derecho canónico americano. Tercera edición, corregida y completada con las más recientes disposiciones canónicas, por Carlos Silva Cotapos, canónigo teologal de la iglesia metropolitana y secretario de cámara del arzobispo de Santiago de Chile (Friburgo de Brisgovia, Herder, 1909).

${ }^{36}$ Decreto de 11 mayo 1904, en BEAS. 16 (1904-1907), p. 80 n. 129.

${ }^{37}$ Salinas Araneda, Carlos, El primer aporte, cit. (n. 6), pp. 324-325.

${ }^{38}$ LEÓn XIII, epistola Literas a vobis, a los obispos de Brasil, de 2 julio 1894.

${ }^{39}$ Pontificia Commissio pro America Latina, Acta et decreta Consilii Plenarii Americae Latinae in urbe celebrati anno Domini MDCCCXCIX (Roma, 1906, ed. facs. Cittá del Vaticano, Librería Editrice Vaticana, 1999). 
a ello, los obispos de la provincia eclesiástica de Chile se reunieron el 4 de septiembre de 1912 "para celebrar la asamblea trienal que prescribe el artículo 208 del Concilio Plenario de la América Latina”. Lo hicieron en la sala de despacho del arzobispo de Santiago, con la asistencia del propio arzobispo, Juan Ignacio González Eyzaguirre; del obispo de La Serena, Ramón Ángel Jara; del obispo de Concepción, Luis Enrique Izquierdo; y del obispo de Ancud, fray Pedro Armengol Valenzuela. Sirvió de secretario Carlos Silva Cotapos, a la sazón secretario de cámara del arzobispo de Santiago.

"El primer objeto de esta asamblea fue estudiar los dos primeros libros del proyecto de Código de Derecho Canónico enviado a los señores obispos por N. S. Padre Pio X, a fin de que informen acerca de las modificaciones o enmiendas que convenga introducir en é ' $^{\prime 40}$. A ello dedicaron las sesiones de los días 4, 5 y 6 de septiembre. El resultado de estas reuniones de trabajo se recogió en el informe que los prelados chilenos enviaron a Roma. Sin embargo, no todas las observaciones recogidas en el acta fueron incorporadas en el informe final.

\section{Observaciones recogidas en el informe.}

El informe está recogido en dos hojas en folio escritas en latín por un solo lado $^{41}$. No lleva título, sino que se inicia con la fecha, en Santiago de Chile, el 10 de septiembre de 1912, y en él se recogen nueve observaciones numeradas correlativamente con números romanos, precedidas de una breve introducción en la que el metropolitano y los obispos sufragáneos de la provincia chilena manifestaban que enviaban las observaciones que les había sugerido la lectura de los dos libros enviados desde Roma el 20 de marzo de $1912^{42}$. A decir verdad, las observaciones se refieren sólo al libro II, De personis, pues el libro I: Normae generales, al tenor del informe, no les mereció ninguna observación. Si la respuesta debía ser enviada en los seis meses siguientes, los obispos de Chile respondieron dentro de plazo, pero casi al término del mismo. Presento a continuación las observaciones de los obispos chilenos a los libros I y II, a decir verdad sólo al libro II, en el mismo orden en que fueron incluidas en el informe enviado a Roma.

a) Numeración sucesiva de los cánones: observaban los obispos la conveniencia de que todos los cánones del código estuvieran sometidos a una única numeración que, iniciada en el primero de los cánones, siguiera sucesivamente hasta el final, evitando de dar inicio a la numeración en cada uno de los libros ${ }^{43}$. Esta observación tenía su origen en la numeración que presentaban los cánones en los proyectos de los dos libros enviados; en efecto, el libro I empezaba en el

\footnotetext{
${ }^{40}$ Retamal Fuentes, Fernando, cit. (n. 18), vol. II, tomo III, p. 1264. Los proyectos les habían sido enviados el 20 de marzo de 1912, según consta en el informe enviado a Roma.

${ }^{41}$ El original en ASV. CIC 1917, caja 85.

42 "Sancti Jacobi de Chile die 10 septembris 1912. Metropolita et Antistites Suffraganei Provinciae Chilensis ad Emam. Vestram mittunt animadversiones in Juris Canonici Schema ad eos sub die 20 Martii vertentis anni, missum, quae sequuntur". En adelante lo citaré como Animadversiones.

${ }^{43}$ Animadversiones I: "Optandum est un omnes Codicis canones succesiva et una tantum numeratione prosequantur usque in finem, non autem ab initio cuyusque libri".
} 
canon 1 y terminaba en el canon 79, en tanto que el libro II empezaba de nuevo en el canon 1 y terminaba en el canon 567. Esta propuesta fue la primera de las sugeridas por el secretario de cámara del arzobispo de Santiago, Carlos Silva Cotapos, a quien el arzobispo González le había encargado que estudiase el proyecto. Según el acta de la sesión episcopal del 5 de septiembre, se conocieron en ella las observaciones hechas por el secretario, la primera de la cuales era "que se pidiese que dicho Código tuviese una numeración seguida de principio a fin para todos sus cánones y no numeración propia los cánones de cada libro, como es la del proyecto, a fin de que sea más fácil la cita de los cánones" ${ }^{44}$.

Parece que nunca estuvo en la idea de los codificadores que la numeración de los cánones se iniciara de nuevo en cada uno de los libros del código finalmente a aprobar $^{45}$. En efecto, en una circular de 6 de abril de 1904 atribuible al secretario de la Comisión, Pedro Gasparri, dirigida a los rectores de las universidades católicas para pedirles el concurso "en esta empresa importante y difícil"'46, se afirmaba la intención del papa de "distribuir metódicamente todo el derecho canónico en cánones o artículos, a la manera de los códigos modernos", los cuales, como sucedía con los códigos chilenos ya promulgados, daban una numeración única a su articulado. Pero la elaboración parcializada del código canónico y la entrega parcial de los proyectos que se iban terminando hacía aconsejable una numeración igualmente parcializada. De hecho, el código que entró en vigencia tiene una única numeración para los cánones en él recogidos. El texto final, en consecuencia, coincidió con la observación de los obispos chilenos, pero es posible pensar que no porque ellos lo insinuaran, sino porque así estaba diseñado desde un principio.

b) Adquisición de domicilio: la segunda observación de los obispos chilenos se refería al canon 6 del libro segundo, situado al inicio del libro De personis, entre los cánones generales del mismo. Pedían los obispos que en el parágrafo 1 de dicho canon se dijera "o bien prolongada a un bienio completo" en lugar de un decenio completo ${ }^{47}$. Se trataba del canon que definía cómo se adquiría el domicilio y el cuasidomicilio, y el origen de la propuesta estaba en una observación del obispo de Ancud, fray Pedro Armengol Valenzuela, quien en la sesión episcopal del 4 de septiembre había iniciado su intervención sugiriendo " 1 ", que se reduzca a dos años el plazo de diez que el canon 6 del libro II exige para que la residencia constituya domicilio" ${ }^{4}$. Según el parágrafo 1 del canon 6 del libro II, "el domicilio se adquiere por la residencia en alguna parroquia o cuasiparroquia, siempre que la residencia, o vaya acompañada de la voluntad de permanecer en aquel lugar perpetuamente, si no

${ }^{44}$ Retamal Fuentes, Fernando, cit. (n. 18), vol. II, tomo III, p. 1265.

${ }^{45}$ En un texto elaborado por el futuro cardenal Gasparri para ser discutido en una de las reuniones iniciales de cardenales referidas a la codificación, se hace relación de lo tratado y acordado en una reunión anterior de cardenales convocada por expreso deseo del papa para responder a unas dudas que el Romano Pontífice les había sometido, dice que todos habían admitido la conveniencia de hacer un código compendioso, de toda la legislación eclesiástica, distribuido con orden lógico y por artículo, a modo de los recientes códigos civiles.

${ }^{46}$ Circular Perlegisti, en ASS. 37 (1904-1905), pp. 130-131.

${ }^{47}$ Animadversiones II: "In libro II, can. VI, $\mathbb{1}$ 1, dicatur: 'vel protracta ad biennium completum', loco decennium completum". En el original subrayado "loco", etc.

${ }^{48}$ Retamal Fuentes, Fernando, cit. (n. 18), vol. II, tomo III, p. 1264. 
hay causa que lo impida, o se prolongue por un decenio completo" ${ }^{49}$. La propuesta significaba reducir de diez a dos los años requeridos para adquirir domicilio.

Se ha dicho que: "El sistema canónico acerca del domicilio se ha inspirado durante siglos en la concepción romana de esta institución, que ha influido también notablemente en las distintas legislaciones civiles" ${ }^{50}$. Dicha inspiración, sin embargo, no impidió que se introdujeran dos innovaciones de importancia, una de las cuales fue un nuevo modo de adquirirlo, al establecer como suficiente la residencia prolongada durante un número definido de años, novedad introducida en el código de $1917^{51}$. "Desde la Glosa, la concepción romanista ha aplicado al domicilio la doctrina de la possessio, distinguiendo su elemento material o corpus y su elemento formal o animus. Para la adquisición del domicilio, según la doctrina tradicional, se requería la conjunción de dos elementos: la intención de habitar en un lugar (animus); y el hecho de habitar allí efectivamente (corpus)" 52 . Sin embargo, la residencia constante y prolongada no era suficiente para adquirir domicilio, porque de los dos elementos, el animus era considerado el esencial. Siendo el elemento esencial, era preciso probarlo adecuadamente, y para ello fue preciso, en ocasiones, acudir a indicios o presunciones, una de las cuales logró particular aceptación: el derecho romano había establecido la presunción según la cual si un estudiante, una vez terminados sus estudios, había continuado residiendo diez años en el mismo lugar donde había hecho sus estudios, adquiría domicilio en ese lugar ${ }^{53}$. La doctrina y la jurisprudencia canónicas aplicaron dicha presunción decenal a todas las personas, transformándola en una presunción de derecho finalmente recibida en el código de 1917.

La observación de los obispos chilenos venía a romper el peso de toda una larga tradición que fijaba en diez años de efectiva residencia el tiempo necesario para adquirir el domicilio. Si, como había quedado claro desde el inicio de la codificación, el nuevo texto debía limitarse a recoger, en forma de código, el derecho vigente, sin innovar salvo en lo necesario ${ }^{54}$, era claro que la propuesta

${ }^{49}$ Proyecto de Libro II, canon $6 \$ 1$ : "Domicilium acquiritur commoratione in aliqua paroecia aut quasi-paroecia, quae commoratio vel coniuncta sit cum animo ibi perpetuo manendi, si nibil inde avocet, vel protracta ad decennium completum".

${ }^{50}$ De Fuenmayor, Amadeo, Comentario al canon 102 del CIC 1983, en Instituto Martín de Azpilcueta, Facultad de Derecho Canónico, Universidad de Navarra, Comentario exegético al Código de Derecho Canónico (Pamplona, Eunsa, 1996), I, pp. 735-736.

${ }^{51}$ La otra novedad fue la introducción del concepto de cuasidomicilio, acuñado por los canonistas y que empezó a abrirse paso a raíz del Concilio de Trento. Ibíd.

52 Ibíd.

${ }^{53}$ Cod. 10, 39 (40), 2.

${ }^{54}$ En un texto elaborado por el futuro cardenal Gasparri, para ser discutido en una de las reuniones iniciales de cardenales referidas a la codificación, que hace relación de lo tratado y acordado en una reunión anterior de cardenales convocada por expreso deseo del papa para responder a unas dudas que el Romano Pontífice les había sometido, dice que todos habían admitido: " $1{ }^{\circ}$ que el actual Corpus iuris canonici debe ser mantenido en su valor jurídico, menos en aquellos puntos que habían sido o que deberían modificarse”. Agregaba Gasparri que el papa deseaba que los cardenales reconsideraran libremente la necesidad o la oportunidad de poner en obras esta nueva colección, teniendo presente, entre otras, las siguientes observaciones: i) se considera un punto cierto que las leyes precedentes conservarían su vigor a menos que fuesen 
de los prelados chilenos no podía tener acogida, sobre todo, si la reducción del plazo resultaba drástica.

El texto final, una vez aprobado el código, varió respecto del proyecto de 1912, pero la variación no fue en lo relativo al plazo, que se mantuvo, sino en cuanto al lugar de la residencia, que, además de la parroquia y cuasiparroquia, se vio ampliado a la diócesis, vicariato apostólico o prefectura apostólica ${ }^{55}$. Así, la sugerencia de los obispos chilenos no fue acogida.

Parece que la propuesta de los prelados chilenos, que hicieron suya la del obispo Valenzuela, era un tanto audaz; tanto, que ni siquiera el Código de Derecho Canónico de 1983 estableció un plazo tan reducido para la adquisición del domicilio, pues el canon 102 en actual vigencia, en su $₫ 1$ dispone que el domicilio se adquiere por la residencia en el territorio de una parroquia o al menos de una diócesis, que o vaya unida a la intención de permanecer allí perpetuamente si nada lo impide, "o se haya prolongado por un quinquenio completo".

c) Eliminación de una sílaba en el canon 23. La tercera observación de los obispos chilenos se refería al canon 23 del libro II, situado en el título sobre la adscripción de los clérigos a la diócesis o iglesia ${ }^{56}$, y se trataba de una observación meramente formal. Sugerían los obispos que en dicho canon se eliminase la sílaba "cit." ${ }^{2}$. El autor de esta propuesta es Carlos Silva Cotapos quien, en la sesión episcopal del 5 de septiembre, incluyó como proposición cuarta la siguiente: " $4^{\circ}$, Que en el canon 23 del libro II se suprima la abreviatura 'cit'., que parece redundante" 58 .

Según este canon 23, también por la profesión religiosa quedaba uno excardinado de la propia diócesis según la norma del canon 458 del Schema ${ }^{59}$. La observación de los obispos, como se ve, no era una observación de fondo sino tan sólo referida a la redacción del canon; y era lo suficientemente fundada como para

modificadas por el código, caso en el cual éstas tendrían valor prevalente; ii) los artículos del nuevo código, en la medida de lo posible, mantendrían el mismo tenor literal de las leyes de que habían sido tomados.

${ }^{55} \mathrm{CIC}$ 1917, canon $92 \$ 1$ : "El domicilio se adquiere por la residencia en alguna parroquia o cuasiparroquia, o por lo menos en una diócesis, vicariato apostólico o prefectura apostólica, siempre que la residencia, o vaya acompañada de la voluntad de permanecer en aquel lugar perpetuamente, si no hay causa que lo impida, o se prolongue por un decenio completo". Se trató de una novedad introducida por el Codex, pues según el derecho de las decretales sólo era posible el domicilio parroquial y sólo mediante éste se adquiría el domicilio diocesano. Con el código, en cambio, fue posible directamente adquirir domicilio diocesano sin tener domicilio parroquial. Cabreros de Anta, cmf., Marcelino; Alonso Lobo, op., Arturo; Alonso Morán, op., Sabino, Comentarios al Código de Derecho Canónico (Madrid, BAC, 1963), I, p. 311. Sobre la historia del domicilio canónico se puede ver Delgado Galindo, Miquel, El domicilio canónico (Pamplona, Eunsa, 2006), pp. 29-48.

${ }^{56}$ Liber secudus, De personis; Pars prima, De clericis; Sectio I, De clericis in genere; Titulus I, De clericorum adscriptione alicui dioecesi vel ecclesiae.

${ }^{57}$ Animadversiones III: "In can. 23 deleatur syllaba cit". El subrayado es del original.

${ }^{58}$ Retamal Fuentes, Fernando, cit. (n. 18), vol. II, tomo III, p. 1265.

${ }^{59}$ Proyecto de Libro II, canon 23: "Etiam per proffesionem religiosam quis a propria dioecesi excardinatur ad norman tamen cit. can. 458" = "También por la profesión religiosa queda uno excardinado de la propia diócesis, según la norma citada en el canon 458". 
que fuera acogida en el texto final, que no sólo eliminó la sílaba "cit." incluida en el proyecto, sino también el adverbio "tamen" que la acompañaba ${ }^{60}$.

d) Sustituir una remisión interna mal hecha: la cuarta de las observaciones se refiere al canon 84 del libro II, situado en el capítulo de la postulación como modo de hacer la provisión de un oficio eclesiástico ${ }^{61}$. Los obispos sugerían que en el parágrafo 2 de este canon se cambiase la frase "según la norma del canon 76" por la frase “según la norma del canon 77”. Se trataba de otra observación meramente formal y su origen estuvo en una sugerencia formulada por el obispo de La Serena, Ramón Ángel Jara, en la sesión episcopal del 4 de septiembre. Según el acta de dicha sesión, "el Iltmo. Señor Jara indicó por su parte que la cita que se hace en el canon 84 , párrafo $2^{\circ}$ del libro II está errada, pues debe hacerse al canon 77 y no al $76^{\prime \prime 2}$.

El parágrafo 2 del canon 84 se situaba en el caso de que la postulación fuera admitida $^{63}$; en dicho evento, la postulación debía ser comunicada al postulado, el cual debía responder según la norma del canon $76^{64}$. Este último canon, sin embargo, referido a las elecciones como modo de asumir un oficio eclesiástico, disponía quien debía ser elegido y proclamado por el presidente de un colegio, en circunstancias que el canon siguiente, el $77^{65}$, disponía la obligación de comunicar la elección al elegido y lo que éste debía de hacer una vez conocido tal hecho.

Parece claro que la referencia al canon 76 estaba equivocada y que la referencia correcta era al canon 77 . El canon 76 del proyecto pasó a ser el canon $174 \mathrm{del}$ Codex, en tanto que el canon 77 del proyecto pasó a ser, con algunas modificaciones, el canon 175 del Codex ${ }^{66}$. En el código, en consecuencia, la cita correcta debía hacerse al canon 175 y así lo hizo el parágrafo 2 del canon 182 que fue el canon del Codex que recogió el canon 84 del proyecto. En otras palabras, la observación de los prelados chilenos fue acogida o, al menos, tomada en cuenta.

${ }^{60}$ CIC 1917, canon 115: "También por la profesión religiosa queda uno excardinado de la propia diócesis, a tenor del canon 585”.

${ }^{61}$ Liber secundus, Depersonis; Pars prima, De clericis; Sectio I, De clericis in genere; Titulus IV, De officiis ecclesiasticis; Caput III, De postulatione.

${ }^{62}$ Retamal Fuentes, Fernando, cit. (n. 18), vol. II, tomo III, p. 1264.

${ }^{63}$ Proyecto de libro II, canon $84 \$ 2$ : "Quod si postulatio admissa fuerit, id significetur postulato, qui respondere debet ad normam can. 76" = "Si la postulación fue admitida, ha de comunicarse esto al postulado, el cual debe responder según la norma del canon 76 ".

${ }^{64}$ Proyecto de libro II, canon 76: "Is electus habeatur et a collegii praeside proclametur, qui requisitum suffragiorum numerum retulerit, ad normam can. 14" = "Se tendrá por elegido y será proclamado por el presidente del colegio aquel que hubiese obtenido el número de votos requerido a tenor del canon 14 ".

${ }^{65}$ Proyecto de libro II, canon 77: "Electio illico intimanda est electo, qui debet statim vel saltem infra triduum a recepta intimatione manifestare utrum electioni consentiat, an eidem renuntiet" = "La elección debe ser notificada al elegido inmediatamente, quien debe manifestar al momento, o bien por lo menos en un plazo de tres dias, que consiente su elección, o bien, que renuncia a ella".

${ }^{66}$ CIC 1917, canon 175: "La elección se ha de notificar inmediatamente al elegido, el cual, por lo menos dentro de los ocho días útiles después de recibida la notificación, debe manifestar si acepta la elección o si renuncia a la misma; de lo contrario, pierde todo derecho adquirido por la elección". 
e) Visita episcopal a conventos de religiosos exentos en regiones apartadas de la Urbe. La quinta observación de los obispos se refería al canon 242 del proyecto de libro II, que establecía quiénes estaban sometidos a la visita episcopal y quiénes quedaban exentos de la misma ${ }^{67}$. Pedían los prelados que se agregare un parágrafo que, con éstas u otras palabras semejantes dispusiere, que "en las regiones apartadas de la Urbe los obispos pueden visitar los conventos de los religiosos exentos solamente para informar a la Santa Sede en las visitas ad limina"68. El origen de esta sugerencia estuvo en el obispo de Concepción, Luis Enrique Izquierdo, quien se refirió a él en la última sesión episcopal dedicada a estudiar estos dos libros: "en este día, el Iltmo. Obispo de Concepción, a propósito del canon 242 hizo indicación para que se pidiese facultad para que los obispos de regiones apartadas, como la América Meridional y Filipinas, pudiesen visitar, sólo ad referéndum a los religiosos cuando hubiesen de hacer la Visita ad limina Apostolorum, a fin de poder dar cuenta a la Santa Sede de dichas comunidades, con mejor conocimiento de causa. Esta indicación también fue aceptada y con ella se dio por terminado el estudio del nuevo Código Canónico" ${ }^{\text {. }}$.

Explicaba Donoso ${ }^{70}$ que, según el derecho común, todos los monasterios y religiosos que los habitaban, al igual que los clérigos seculares, estaban sujetos a la jurisdicción ordinaria de los obispos en cuyas diócesis existían los monasterios o casas religiosas. Con el tiempo, sin embargo, los regulares habían ido obteniendo diversos privilegios, uno de los cuales era la exención de la potestad de los obispos, hasta que diferentes órdenes regulares, especialmente los mendicantes, habían quedado completamente exentas no sólo de la ley diocesana, esto es de las leyes que establecían diversas contribuciones como el catedrático ${ }^{71}$, la cuarta decimal $^{72}$, la cuarta funeral ${ }^{73}$ y otras, sino de la ley de jurisdicción, es decir, de aquellos actos en los que el obispo confería algo, como la colación de órdenes u otros sacramentos, la consagración de iglesias o altares, o la administración de justicia. Había, empero, casos especiales en que los obispos, a pesar de la exención, podían ejercer jurisdicción ordinaria o delegada, que el propio Donoso enumeraba

\footnotetext{
${ }^{67}$ Liber secundus, De personis; Pars prima, De clericis; Titulus VIII, De potestate episcopali iisque qui de eadem participant; Caput I, De Episcopis.

${ }^{68}$ Animadversiones V: "In can. 242 addatur incisum haec vel similia verba continens: In regionibus ab Urbe dissitis possunt Episcopi visitare conventus religiosorum exemptorum ad hoc tantum, ut Sanctam Sedem doceant in visitatione ad limina" = "En el canon 242 que se agregue un inciso que con estas palabras u otras semejantes sostenga: En las regiones apartadas de la Urbe los obispos pueden visitar los conventos de religiosos exentos solamente para informar a la Santa Sede en la visita ad limina".

${ }^{69}$ Retamal Fuentes, Fernando, cit. (n. 18), vol. II, tomo III, pp. 1265-1266.

${ }^{70}$ Donoso, Justo, cit. (n. 16), I, pp. 191-192.

${ }^{71}$ Era la erogación de dos sueldos o escudos de oro que podía exigir anualmente el obispo de todos los párrocos y otros beneficiados, y de las iglesias seculares de su diócesis; se llamaba catedrático en honor de la cátedra episcopal. Donoso, Justo, ibíd., p. 199.

${ }^{72} \mathrm{La}$ cuarta decimal era la cuarta parte de los legados que se dejaban a una iglesia o lugar pío de la diócesis. Ibíd., p. 200.

${ }^{73} \mathrm{La}$ cuarta funeral o funeraria se deducía de la cantidad designada para gastos en los funerales. Ibíd.
} 
someramente $^{74}$. Era esta limitación la que motivaba al obispo de Concepción a formular la agregación de este parágrafo al canon 242.

Según el canon 242 del Schema ${ }^{75}$, estaban sometidos a la visita episcopal ordinaria las personas, las cosas y los lugares sagrados, aunque fuesen exentos, que se encontrasen en el ámbito de la diócesis, a no ser que hubiese una excepción especial para la visita, concedida por la Sede Apostólica $(\$ 1)$. A la misma visita estaban sometidas las iglesias parroquiales de los regulares, pero en éstas sólo en lo referido a la cura espiritual de los fieles y la administración de los sacramentos, según el canon 503 del proyecto $(\$ 2)$. También podía el obispo visitar a los religiosos exentos en los casos expresamente señalados en los cánones que se enumeraban ${ }^{76}(\$ 3)$. A este canon debía agregarse, según los prelados chilenos, un nuevo parágrafo, permitiendo la visita episcopal a los conventos de los religiosos exentos para el solo efecto de estar mejor informados al momento de hacer los obispos la visita ad limina a Roma, y sólo respecto de los obispos de diócesis alejadas de Roma como eran las diócesis chilenas.

El canon 242 del Schema pasó a ser el canon 344 del Codex $^{77}$ : el parágrafo primero del proyecto se recogió, con algunos retoques; el parágrafo segundo fue eliminado, y el tercero se mantuvo, con una redacción más rigurosa, en la que se dispuso por regla general que "a los religiosos exentos unicamente puede el obispo visitarlos en los casos expresados en el derecho". La sugerencia chilena, en consecuencia, no fue acogida.

f) Agregar nuevos privilegios a los que gozan los obispos residenciales desde que reciben noticia auténtica de su provisión canónica. Era la sexta petición de los prelados chilenos ${ }^{78}$ y estaba referida al canon 247 en el que se definían algunos de los derechos que correspondían a los obispos residenciales $^{79}$ desde que habían tomado posesión de su obispado ${ }^{80}$. Pedían que en

${ }^{74}$ Ibíd., pp. 192-199.

${ }^{75}$ Proyecto de libro II, canon 242: "\$ 1 . Ordinariae episcopali visitatione obnoxiae sunt personae, res ac loca pia, quamvis exempta, quae intra dioecesis ambitum continentur, nisi specialis a visitatione exemptio fuerit ipsis ab Apostolica Sede concessa. \$2. Eidem visitationi subiectae sunt Regularium quoque Ecclesiae paroeciales, sed in iis tantum quae spiritualem curam fidelium et sacramentorum administrationem spectant, ad normam can. 503. $\$ 3$. Potest episcopus visitare religiosos etiam exemptos in casibus expressis in can. $377 n^{\circ} 1 ; 382 ; 39553$ et 4".

${ }^{76}$ Véase nota anterior $\$ 3$. Se trataba de situaciones de excepción, que no recogían la posibilidad sugerida por el obispo de Concepción y que fueron notablemente reformadas en el texto final del código.

${ }_{77}$ CIC 1917, canon 344: " $\$ 1$. Están sujetos a la visita Episcopal ordinaria las personas, cosas y lugares piadosos, aunque sean exentos, que se hallan dentro del ámbito de la diócesis, siempre que no pueda probarse que la Sede Apostólica les ha concedido especial exención de la visita. $\$ 2$. Pero a los religiosos exentos únicamente puede el Obispo visitarlos en los casos expresados en el derecho".

${ }^{78}$ Animadversiones VI: "In can. $247 \$ 2 n^{\circ} 2$, post verba quinquaginta dierum addatur: et indulgentiam plenariam in assumptione muneris et post visitationem pastorales cujusque paroveciae. I Et ad calcem ejusdem canonis ponantur privilegia Emis. Cardinalibus concessa in art. 140 \$ 1 $n^{\circ} 7^{\circ}, 8^{\circ}$ et $9^{\circ}$ ". En el original, subrayado “et", etc.

${ }^{79}$ Obispo residencial es el que posee la jurisdicción sobre una diócesis determinada.

${ }^{80}$ Liber secundus, De personis; Pars prima, De clericis; Titulus VIII, De potestate episcopali iisque qui de eadem participant; Caput I, De Episcopis. 
el canon $247 \$ 2 \mathrm{n}^{\circ} 2$ del proyecto ${ }^{81}$, después de la palabra “cincuenta días", se agregase la frase "y la indulgencia plenaria en la asunción del cargo y después de la visita pastoral a cada parroquia". Pedían, igualmente, que al final del mismo canon se agregasen a los obispos residenciales los privilegios concedidos a los cardenales en el canon $140 \$ 1 \mathrm{n}^{\circ} 7,8$ y $9^{82}$.

La petición de los prelados chilenos significaba que el obispo residencial, desde que tomaba posesión de su cargo, tendría, además del derecho de conceder 50 días de indulgencia en los lugares de su jurisdicción, el derecho a conceder indulgencia plenaria al asumir su cargo, y conceder la misma indulgencia plenaria después de la visita pastoral a cada parroquia ${ }^{83}$. A lo anterior se agregaban: i) la facultad de ganar en su propio oratorio las indulgencias para cuya adquisición estuviese prescrita la visita de algún templo o de alguna capilla pública de la ciudad o lugar en el cual los obispos se hallasen actualmente, pudiendo gozar de este privilegio también sus familiares (can. $140 \$ 1 \mathrm{n}^{\circ} 7$ ); ii) la facultad de bendecir en todas partes, con sola la señal de la cruz, aplicando todas las indulgencias que solía conceder la Santa Sede, rosarios y otras coronas deprecatorias, cruces, medallas, estatuas, escapularios aprobados por la Santa Sede e imponerlos sin obligación de inscribir los nombres (can. $140 \$ 2 \mathrm{n}^{\circ} 8$ ); iii) la facultad de erigir con una sola bendición, en las iglesias y oratorios, aunque fuesen privados, en los que se podía

${ }^{81}$ Proyecto de libro II, canon $247:$ “ $\$ 2$. A capta vero possessione episcopi residentiales habent praeterea ius: $1^{\circ}$ Ut in omnibus Missis quae in propria dioecesi celebrentur tum a religiosis tum a saecularibus, nominentur in canone, ac die anniversaria suae praeconizationis et consecrationis fiat collecta eiusdem anniversarii. $2^{\circ}$ Concedendi indulgentias quinquaginta dierum in suae iurisdictionis locis. $3^{\circ}$ Elevandi in omnibus ecclesiis suae dioecesis thronum cum baldachino" = "Los obispos residenciales, desde que toman posesión, tienen además derecho: $1^{\circ}$ Que en todas las Misas que sean celebradas en su propia diócesis, ya por los religiosos ya por los seculares, sean nombrados en el canon, y en el día aniversario de su preconización y de su consagración, que se haga una colecta de su aniversario. $2^{\circ}$ A conceder cincuenta dias de indulgencia en los lugares de su jurisdicción. $3^{\circ}$ A levantar trono con baldaquino en todas las iglesias de su diócesis".

${ }^{82}$ Proyecto de libro II, canon 140: "\$ 1 . Praeter privilegia de quibus in can. 9 'De iudiciis', et can. 33 'De delictis et poenis', Cardinales facultate gaudent: $7^{\circ}$ Lucrandi in propriis sacellis indulgentias, ad quas acquirendas praescripta sit visitatio templi alicuius vel publicae aediculae civitatis seu loci, in quo Cardinales actu commorentur, quo privilegio etiam eorum familiares frui possunt. $8^{\circ}$ Benedicendi ubique, solo crucis signo, cum omnibus indulgentiis a Sancta Sede concedi solitis, rosaria, aliasque coronas precatorias, cruces, numismata, statuas, scapularia a Sede Apostolica probata eaque imponendi absque onere inscriptionis. $9^{\circ}$ Sub unica benedictione erigendi in ecclesiis et oratoriis etiam privatis, in quibus Missa celebrari possit, aliisque piis locis, Stationes 'Viae Crucis' cum omnibus indulgentiis, quae huiusmodi exercitium peragentibus impertitae sunt; nec non benedicendi pro fidelibus, qui causa infirmitatis vel alterius legitimi impedimenti sacras Stationes 'Viae Crucis' visitare nequeant, Cricifixi icones cum applicatione omnium indulgentiarum devoto exercitio eiusdem 'Viae Crucis' a Romanis Pontificibus adnexarum”.

${ }^{83}$ El Concilio de Trento (1545-1563) imponía a los obispos la obligación de visitar su diócesis personalmente, o por su vicario general u otra persona si estaba legítimamente impedido, visita que debía hacer todos los años, a menos que la diócesis fuera muy extensa, en cuyo caso la podía hacer en dos años por sí o por visitador (Conc. Trid. sess. 24, cap. 3 de ref.). El tercer Concilio Limense (1582-1583), sin embargo, amonestaba encarecidamente a los obispos que practicasen la visita por sí mismos, y si se veían obligados a nombrar visitadores, que lo hicieran en varones íntegros y probados (Actione 3, cap. 1). 
celebrar Misa, y en otros piadosos lugares, las estaciones del Vía Crucis, con todas las indulgencias concedidas a los que hacían este piadoso ejercicio; y también a favor de los fieles que por enfermedad u otro legítimo impedimento no pudiesen visitar las estaciones del Vía Crucis, de bendecir crucifijos aplicándoles todas las indulgencias concedidas por los Romanos Pontífices al devoto ejercicio del Vía Crucis (can. $140 \$ 2 \mathrm{n}^{\circ}$ 9).

Esta observación tenía su origen en la exposición que había hecho el obispo de Ancud, fray Pedro Armengol Valenzuela en la primera sesión de los prelados chilenos, quien, como segunda propuesta suya, sugería "que se amplien los privilegios que el canon 247 del mismo libro otorga a los Obispos, concediéndoles mayores facultades para otorgar indulgencias, de modo que puedan conceder indulgencia plenaria al tomar posesión de su sede, al terminar la visita pastoral de cada parroquia y de la diócesis entera, etc., etc. y que se les comuniquen los privilegios cardenalicios contenidos en los $n n^{\circ} 8^{\circ}$ y $9^{\circ}$ del canon 160 del mismo" ${ }^{\prime 4}$. Hay un error en la referencia que hace el acta de esta sesión episcopal al canon 160 del proyecto del libro II, error que se corrigió en el informe enviado a Roma, pues el canon 160, además que regulaba las atribuciones de la Cancillería Apostólica, constaba tan sólo de dos parágrafos. Por otra parte, la propuesta del obispo de Ancud se refería sólo a los números 8 y 9 del canon 140, por lo que la facultad del número 7 fue agregada, seguramente, con ocasión de la conversación a que daría origen la propuesta del obispo mercedario.

El canon 247 del libro II del proyecto se convirtió, con modificaciones especialmente en el parágrafo 1 , en el canon 349 del código promulgado ${ }^{85}$. Pero las variantes introducidas no recogieron las sugerencias de los obispos chilenos. En efecto, el número 2 del parágrafo 2 de dicho canon, que había sido objeto de su atención, no sufrió cambio alguno y entró en vigencia en los mismos términos que habían conocido los prelados en 1912. Y no se agregó al final del canon las facultades que el proyecto otorgaba a los cardenales, las que siguieron siendo sólo cardenalicias con la entrada en vigencia de Codex.

g) Tiempo de cesación de los examinadores sinodales y de los párrocos consultores elegidos en sínodo o fuera de él. La séptima sugerencia de los obispos chilenos se refería a un canon muy próximo al anterior, el canon $259^{86}$, un extenso canon que trataba de los examinadores sinodales y los párrocos consultores elegidos en el sínodo diocesano ${ }^{87}$. La sugerencia de los obispos chilenos se centraba en el parágrafo $5^{88}$, y pedía ampliar a seis, en vez de cinco, el

${ }^{84}$ Retamal Fuentes, Fernando, cit. (n. 18), vol. II, tomo III, p. 1264.

${ }^{85}$ CIC 1917, canon 349: "\$2. Los Obispos residenciales, desde que toman posesión, tienen además derecho: $1^{\circ} \mathrm{A}$ percibir las rentas de la mesa episcopal; $2^{\circ} \mathrm{A}$ conceder cincuenta días de indulgencia en los lugares de su jurisdicción; $3^{\circ} \mathrm{A}$ levantar trono con baldaquino en todas las iglesias de su diócesis".

${ }^{86}$ Liber secundus, De personis; Pars prima, De clericis; Titulus VIII, De potestate episcopali iisque qui de eadem participant; Caput III, De Sinodo diocesana.

${ }^{87}$ Animadversiones VII: "In can. 259 S 5, substituatur post quinquennium verbis post sexennium" = "En el can. $259 \$ 5$ que se sustituya después de un quinquenio por las palabras después de un sexenio". En el original, subrayados las expresiones en subtitución.

${ }^{88}$ Proyecto de libro II, canon 259: “\$5. Examinatores et parochi consultores, sive in synodo 
número de años en que cesaba el nombramiento de los examinadores sinodales y de los párrocos consultores, elegidos en sínodo o fuera de él, sin perjuicio de que pudieren ser elegidos de nuevo. El origen de esta propuesta estuvo en las sugerencias hechas por el secretario Carlos Silva Cotapos en la sesión episcopal del 5 de septiembre de 1912, la quinta de las cuales proponía "que en el canon 259 S 5 se diga que los párrocos consultores duran en su cargo seis años, porque ese es el período para la celebración de los sinodos en que se les debe nombrar" 89.

Según un concepto moderno, el sínodo diocesano "es una asamblea de sacerdotes y de otros fieles escogidos de una Iglesia particular, que prestan su ayuda al obispo de la diócesis para bien de toda la comunidad diocesana" ${ }^{90}$. Dispuso el Concilio de Trento $^{91}$ que se celebrara anualmente, pero, como lo hacía presente Donoso $^{92}$, "sensible es en extremo que, en América, donde son tanto más graves las necesidades espirituales, y tanto más necesaria, por diferentes causas, la frecuente celebración de Sínodos Diocesanas, se haya hecho tan poco caso de este punto tan importante de la disciplina eclesiástica, que son raros los obispos que las hayan convocado una vez en su vida”.

Disponía el tridentino que en la reunión sinodal se nombrasen examinadores sinodales, que debían ser eclesiásticos, maestros, doctores o licenciados en teología o derecho canónico o bien otros clérigos seculares o regulares idóneos, para que, en unión con el obispo, examinasen a los que se presentaban a concurso para la provisión de las parroquias vacantes. Su oficio duraba hasta la celebración del siguiente sínodo que debía hacerse al año siguiente. Podían ser nombrados por el obispo, con aprobación del cabildo eclesiástico, si alguno de los elegidos en el sínodo fallecía o se ausentaba por largo tiempo; en estos casos, su nombramiento duraba hasta la celebración del siguiente sínodo ${ }^{93}$.

Los párrocos consultores fueron de creación posterior, en fecha muy próxima a la consulta hecha a los obispos chilenos, pues fueron creados por el decreto Maxima cura de la Sagrada Congregación Consistorial, de 20 de agosto de $1910^{94}$, con la tarea de intervenir en los procesos administrativos de remoción y de traslado de párrocos.

Según el parágrafo 5 del canon 259 del proyecto, los examinadores sinodales y los párrocos consultores, ya fueran elegidos en el sínodo o fuera de él, duraban cinco años en sus funciones o hasta que se celebrara un nuevo sínodo, si el plazo era menor. La sugerencia de los obispos chilenos era ampliar el plazo en un año, de cinco a seis años. ¿La razón? Era una sugerencia meramente formal, pues se

sive extra synodum electi, post quinquennium a sua nominatione vel etiam prius, adveniente nova Synodo, officio cadunt; possunt tamen, servatis de iure servandis, denuo eligi" = "Los examinadores y párrocos consultores, elegidos en el sinodo o fuera de él, después de un quinquenio de su nominación o antes, al celebrarse un nuevo sinodo, cesan en el oficio; sin embargo, pueden ser elegidos de nuevo, observando lo que por derecho haya que observar".

${ }^{89}$ Retamal Fuentes, Fernando, cit. (n. 18), II, 3, p. 1265.

${ }^{90}$ CIC 1983, canon 460.

${ }^{91}$ Conc. Trid. sess. 24 , cap. 2 de ref.

${ }^{92}$ Donoso, Justo, cit. (n. 16), I, p. 34.

${ }^{93}$ Ibíd., pp. 30-33.

${ }^{94}$ AAS. 2 (1910), p. 639. 
trataba de poner en relación el parágrafo 5 del canon 259 con el parágrafo 1 del canon 254 del proyecto de libro II, en el cual se disponía que la celebración de los sínodos sería cada seis años ${ }^{95}$. Si los examinadores sinodales y los párrocos consultores debían ser nombrados en el sínodo, era lógico que su oficio expirase a los seis años, pues en ese sexto año debía celebrarse un nuevo sínodo que debía proceder a un nuevo nombramiento. Es por lo que Silva Cotapos razonaba su propuesta diciendo que "ese es el período para la celebración de los sinodos en que se les debe nombrar".

El parágrafo 5 del canon 259 del proyecto pasó, con modificaciones, a ser el parágrafo 1 del canon 387 del Codex, y en él se hizo la concordancia exacta, afirmando que "los examinadores y los párrocos consultores, ya hubieran sido nombrados en el Sinodo, ya fuera de él, cesan en el cargo a los diez años de su nombramiento,o antes, si se celebra nuevo Sinodo". La referencia a los diez años concordaba con el canon $356 \$ 1$ del código piobenedictino, según el cual "en todas las diócesis se debe celebrar, al menos cada diez años, Sinodo diocesano".

La advertencia surtió efecto y, aunque cambió el número de años en que debían celebrarse los sínodos diocesanos, en el texto final se tuvo cuidado de hacer la concordancia exacta.

h) Propiedad de los bienes adquiridos por un religioso que, por la profesión, ha perdido el dominio de los bienes y es promovido a la dignidad episcopal u otra fuera de la propia religión. La octava sugerencia de los obispos chilenos se refería al canon 500 del libro II $^{96}$, que definía el destino de los bienes adquiridos por un religioso después de ser promovido a la dignidad episcopal u otra fuera de la propia religión ${ }^{97}$. Sugerían que en el número

${ }^{95}$ Proyecto de libro II, canon 254: "\$ 1 . In singulis dioecesibus celebranda est sexto saltem quoque anno dioecesana Synodus; in qua de iis tantum agendum quae ad particulares cleri populique dioecesis necessitates vel utilitates referuntur" = "En todas las diócesis se debe celebrar, al menos cada seis años, Sinodo diocesano, en el cual únicamente se tratará de las cosas concernientes a las necesidades o utilidad particulares del clero y pueblo de la diócesis". Este canon pasó a ser el canon 356 del Codex, manteniendo la redacción pero cambiando la frecuencia del sínodo a diez años.

${ }^{96}$ Liber secundus, De personis; Pars secunda, De religiosis; Titulus XIII, De obligationibus et privilegiis religiosorum; Caput III, De obligationibus et privilegiis religiosi ad ecclesiasticam dignitatem promoti vel paroeciae regendae destinati.

${ }^{97}$ Proyecto de libro II, canon 500: "Salvi privilegiis et indultis a Sede Apostolica concessis, religiosus ad dignitatem episcopalem vel aliam extra propriam religionem evectus: $1^{\circ}$ Si per professionem bonorum dominium amiserit, bonorum, quae ipsi obveniunt, habet usum, usumfructum et administrationem; proprietatem vero acquirit ad normam can. $456.2^{\circ}$ Si per professionem bonorum dominium non amiserit, bonorum quae habebat, recuperat usum, usumfructum et administrationem; quae postea ipsi obveniant, sibi plene acquirit. $3^{\circ}$ Omnes vero bona, quae ipsis obveniunt non intuitu personae, acquirunt et de ipsis debent disponere iuxta offerentium voluntatem" = "Salvo privilegios e indultos concedidos por la Sede Apostólica, el religioso promovido a la dignidad episcopal u otra fuera de su propia religión: $1^{\circ}$ Si por la profesión habia perdido el dominio de los bienes, tiene el uso, usufructo y administración de los que ahora le vengan; en cuanto a la propiedad adquiere según la norma del can. 456. $2^{\circ}$ Si por la profesión no habia perdido el dominio de los bienes, recobra el uso, usufructo y administración de los que tenía; y los que recibe después los adquiere plenamente para sí. $3^{\circ}$ En cuanto a todos los bienes, los que reciba no por consideración a su persona, debe disponer según la voluntad de los donantes". 
$1^{\circ}$ del canon 500, que trataba del caso del religioso que, por su profesión religiosa había perdido el dominio de los bienes, en lugar de decirse que la propiedad la adquiría según la norma del canon $456^{98}$, se dijese que la adquiría para la iglesia o para la diócesis ${ }^{99}$.

El autor de esta observación fue también el obispo de Ancud, Pedro Armengol Valenzuela, religioso mercedario, que en la sesión episcopal del 5 de septiembre "propuso que se modificase el canon 500 expresándose en él, que el religioso obispo adquiere para su iglesia, salvo los privilegios especiales que obtenga de la Santa Sede”.

Escribía Donoso ${ }^{100}$ que el estado religioso es "un género o modo estable de vivir en común, aprobado por la Iglesia, en el cual los fieles que lo profesan, se obligan a caminar a la perfección, emitiendo los votos perpetuos de obediencia, pobreza y castidad". Estos tres votos constituyen la esencia del estado religioso, y en virtud del voto de pobreza, el religioso renuncia y queda incapaz de todo dominio y propiedad en los bienes temporales, además que, en lo referido a su uso, no puede hacerlo independiente de la voluntad del superior ${ }^{101}$. El voto de pobreza, sin embargo, no se opone a la posesión en común de bienes, tanto muebles como inmuebles, y el mismo Concilio de Trento lo permitió a las ordenes regulares, incluidos los mendicantes, con excepción de los menores observantes y capuchinos ${ }^{102}$.

Sin perjuicio de lo anterior, el voto de pobreza, siendo común a todos, no siempre era y es vivido de la misma forma por las diversas comunidades religiosas que hay en la Iglesia, las que, en sus propias constituciones, definen el modo de vivirlo, según la naturaleza y fines de cada instituto, naturaleza y fines que determinan el modo de usar los bienes materiales. Lo verdaderamente importante es que el diferente régimen disciplinar no vaya en mengua de la pobreza que, de hecho y espíritu, han de vivir los consagrados.

A la luz de lo anterior, si bien todo religioso profesa el voto de pobreza, las consecuencias del mismo serían diferentes según lo definiesen las respectivas constituciones. Esta diferencia se advertía también cuando el religioso era elevado a la

${ }^{98}$ Proyecto de libro II, canon 456: "Post solemnem professionem, salvis pariter peculiaribus Apostolicae Sedis indultis: $1^{\circ}$ Omnia bona quae quovis modo obveniant regulari, cedunt ordini vel provinciae vel domui secundum constitutiones, si ordo vel provincia vel domus sit capax possidendi in communi et, ubi de haereditatibus agatur, succedendi professis, eorum ratione seu nomine. $2^{\circ}$ In ordine vero incapaci bona acquiruntur Sanctae Sedi in proprietatem, nisi hanc sibi reservaverint ipsi dantes" = "Después de la profesión solemne, salvo peculiar indulto de la Sede Apostólica: $1^{\circ}$ todos los bienes que de cualquier manera adquieren los regulares, pasan a la orden o a la provincia o a la casa según las constituciones, si la orden o la provincia o la casa son capaces de poseer en común y, tratándose de herencias, suceden a los profesos, por su razón o nombre. $2^{\circ}$ En una orden incapaz, los bienes son adquiridos en propiedad por la Santa Sede, a no ser que los donantes los hayan reservado para si".

${ }^{99}$ Animadversiones VIII: "In canone $500 n^{\circ} 1$, loco proprietatem vero acquirit ad normam can. 456 dicatur: proprietatem vero acquirit propriae ecclesiae vel dioecesi" = "En el canon 500 $n^{\circ} 1$ en lugar de que la propiedad la adquiere conforme a la norma del can. 456, que se diga que la propiedad la adquiere la propia iglesia o diócesis".

${ }^{100}$ Donoso, Justo, cit. (n. 16), I, p. 289.

${ }^{101}$ Conc. Trid., sess. 25, cap. 2 de regularibus.

${ }^{102}$ Conc. Trid., sess. 25, cap. 3 de regularibus. 
dignidad episcopal o a otra dignidad fuera de su religión y, en tal calidad, adquiría bienes no obstante su voto de pobreza, pues su calidad de religioso no se perdía al alcanzar la dignidad. Es lo que trataba de resolver el canon 500 del proyecto de libro II que en su número $1^{\circ}$ disponía que el religioso, si por la profesión había perdido el dominio de los bienes, tenía el uso, usufructo y administración de los que ahora le viniesen; pero en cuanto a la propiedad adquiría según la norma del can. 456. En otras palabras, todos los bienes que de cualquier manera adquiría, pasaban a la orden o a la provincia o a la casa según las constituciones, si la orden o la provincia o la casa eran capaces de poseer bienes en común. En cambio, en una orden incapaz, los bienes eran adquiridos en propiedad por la Santa Sede, a no ser que los donantes los hubiesen reservado para sí.

La reforma sugerida por el obispo de Ancud y asumida por los obispos chilenos consistía en que, tratándose de religiosos que habían perdido el dominio de los bienes, una vez elevados a la dignidad episcopal u otra fuera de la orden, si adquirían bienes en tal calidad, estos debían quedar para su iglesia o diócesis, ya se tratase de órdenes con capacidad de poseer bienes en común o sin ella.

La sugerencia de los obispos chilenos fue acogida parcialmente. En efecto, el canon 500 del proyecto de libro II pasó a ser, con modificaciones, el canon 628 del Codex, según el cual, "el religioso promovido a la dignidad episcopal u otra fuera de su propia religión: $1^{\circ}$ Si por la profesión habia perdido el dominio de los bienes, tiene el uso, usufructo y administración de los que ahora le vengan; en cuanto a la propiedad, el obispo residencial, el vicario y el prefecto apostólico la adquieren para la diócesis, vicariato o prefectura; los demás, para la orden o para la Santa Sede, a tenor del canon 582, salvo lo establecido en el canon 239 \1, número 19;”. Esto es, los bienes adquiridos por los obispos residenciales, los vicarios apostólicos y los prefectos apostólicos que eran religiosos eran adquiridos para la respectiva diócesis, vicariato apostólico o prefectura apostólica, tal como lo solicitaban los prelados chilenos que pedían que los bienes adquiridos por estos religiosos pasasen en propiedad para la iglesia o diócesis. Pero el canon aprobado limitó este derecho sólo a los obispos residenciales, a los vicarios apostólicos y a los prefectos apostólicos, pues tratándose de otras dignidades, se volvía a la regla general del canon $582^{103}$, que era el canon que en el Codex había tenido como precedente el canon $456 \mathrm{del}$ proyecto. Conforme a aquél, el religioso que, elevado a una dignidad, adquiría en esta calidad bienes, si pertenecía a una orden capaz de poseer bienes en común, aquéllos eran para la orden, la provincia o la casa según lo dispusiesen las propias constituciones de la orden; si, en cambio, el religioso constituido en dignidad era miembro profeso de una orden incapaz de poseer bienes en común, los bienes que adquiriese constituido en dignidad, pasaban en propiedad a la Santa Sede.

i) Expulsión o dimisión del profeso por enfermedad dolosamente ocultada. La última de las observaciones de los obispos chilenos se refería al

${ }^{103}$ CIC 1917, canon 582: "Después de la profesión solemne, salvos igualmente los indultos peculiares de la Sede Apostólica, todos los bienes que de cualquier modo le vengan al regular: $1^{\circ}$ En Orden capaz de poseer, pertenecen a la Orden, a la provincia o a la casa, según las constituciones determinen. $2^{\circ}$ En una Orden incapaz de poseer los adquiere la Santa Sede en propiedad". 
canon 516 situado entre los cánones referidos a la salida de la religión ${ }^{104}$, cuyo parágrafo 2 afirmaba que la enfermedad no era causa suficiente para la expulsión o dimisión del religioso profeso, a menos que constase con certeza que la había ocultado dolosamente ${ }^{105}$. Sugerían los obispos chilenos ${ }^{106}$ que después de la palabra "reticitam" (= callado), se agregasen las palabras "vel dissimulatam" (= o disimulado). Es decir, que la enfermedad pudiese ser causa suficiente para la expulsión o dimisión del religioso profeso no sólo si había sido callada dolosamente, sino también si había sido disimulada dolosamente.

Esta fue otra sugerencia del único obispo residencial religioso que había en Chile al tiempo de la consulta hecha por Roma, el obispo de Ancud, fray Pedro Armengol Valenzuela, quien, en la sesión episcopal del 5 de septiembre propuso "que el canon 516 se complete la frase 'nisi certo constet eam dolose fuiste reticitam' añadiéndole: 'vel dissimulatam", indicación que también fue aprobada por los demás prelados ${ }^{107}$.

Esta propuesta de los obispos chilenos fue también aceptada. En efecto, el canon 637 del Codex recogió en un único parágrafo parte de lo establecido en el canon 516 del proyecto de libro II. Según el canon que entró en vigencia, "el profeso de votos temporales, cumplido el tiempo de éstos, puede abandonar libremente la religión; asimismo la religión, por causas justas y razonables, puede excluirlo de renovar los votos temporales o de hacer la profesión perpetua; mas no por razón de enfermedad, a no ser que se pruebe con certeza que ya la tenía antes de profesar y que fue dolosamente ocultada o disimulada".

Como puede verse de la simple lectura del canon, la idea propuesta por el obispo Valenzuela y acogida por los demás prelados chilenos aparece expresamente recogida en el canon piobenedictino, incluso, utilizando la misma palabra. No puedo afirmar con certeza que el canon del código aprobado recogió expresamente la sugerencia chilena, pues pudo haber alguna otra propuesta en el mismo sentido. Pero, compartida o no, es claro que, al menos, la idea fue considerada interesante y recogida en el texto finalmente aprobado.

\section{Propuestas no incluidas en el informe enviado a Roma.}

En la reunión de los obispos de la provincia eclesiástica chilena celebrada en septiembre de 1912 en la que, primeramente, se estudiaron los dos primeros libros del proyecto de código canónico que se preparaba en Roma, hubo otras ideas propuestas de las que da cuenta el acta de dicha sesión, pero que no quedaron recogidas en el informe enviado a Roma.

${ }^{104}$ Liber secundus, De personis; Pars secunda, De religiosis; Titulus XV, De egressu e religione.

${ }^{105}$ Proyecto de libro II, canon 516: " $\$ 2$. Infirmitas non est causa sufficiens ad professi eiectionem seu dimissionem, nisi certo constet eam dolose fuisse reticitam" = "La enfermedad no es causa suficiente para la expulsión o dimisión del profeso, a no ser que conste ciertamente que la haya ocultado dolosamente".

${ }^{106}$ Animadversiones IX: "In can. 516 \$2, post verbum reticitam addatur; vel dissimulatam" = "En el canon 516 \$2, después de la palabra callado, agregar o disimulado". El subrayado es del original.

${ }^{107}$ Retamal Fuentes, Fernando, cit. (n. 18),vol. II, tomo III, p. 1265. 
a) Ampliación del privilegio de altar portátil. Hemos visto que la proposición sexta del informe enviado a Roma por lo obispos de Chile, sugería que se ampliasen los privilegios que el canon 247 del proyecto de libro II otorgaba a los obispos residenciales, concediéndoles mayores facultades para otorgar indulgencias e incorporando algunos privilegios que el canon 140 establecía para los cardenales. Esta sugerencia fue planteada por el obispo de Ancud, fray Pedro Armengol Valenzuela, hecha la cual inmediatamente "agregaron a esta indicación los Iltmos. Sres. Izquierdo y Jara que convendría se ampliase el privilegio de altar portátil, de modo que los obispos pudiesen celebrar "etiam in navi' [= incluso en las naves]"108.

Explicaba Donoso ${ }^{109}$ que "hay dos especies de altares, unos fijos y otros portátiles o movibles: unos y otros deben ser de piedra... El altar portátil es un mármol o piedra que se puede trasladar de un lugar a otro. Esta piedra debe ser sólida y de suficiente magnitud para que puedan contener encima el cáliz y la hostia, y también el copón, en caso necesario: se le llama piedra de altar o piedra sagrada y entre nosotros piedra de ara". Por el capítulo Quoniam de privilegiis del Liber Sextus $^{110}$, los obispos tenían el privilegio de celebrar en los altares portátiles, sin que por eso pudiesen violar los entredichos.

Esta sugerencia no fue recogida en el informe enviado a Roma, pero el tema no fue ajeno ni al proyecto de libro II ni al Codex de 1917. En efecto, según el número 1 del parágrafo 1 del canon 247 del proyecto de libro $\mathrm{II}^{111}$, tanto los obispos residenciales como titulares, desde el momento que recibían noticia auténtica de haberse verificado la provisión canónica, podían disfrutar del privilegio de oratorio doméstico y altar portátil en los términos definidos en el canon 99 del libro III, De rebus.

El proyecto de libro III aún no había sido enviado a los obispos y es probable que todavía no estuviera del todo afinado, porque el canon 99 expresamente mencionado se refiere a otra materia, en tanto que la referencia al altar portátil se hace en el canon 101. En efecto, el canon 99 disponía que se podía celebrar el sacrificio de la Misa todos los días, excepto aquellos que el rito del sacerdote exceptuaba ${ }^{112}$. En cambio el canon $101^{113}$ después de afirmar que la Misa debía

${ }^{108}$ Ibíd., p. 1264.

${ }^{109}$ Donoso, Justo, cit. (n. 16), II, p. 73.

${ }^{110}$ In VI, 7, 12.

${ }^{111}$ Proyecto de libro II, canon 247: " $\$ 1$. Ab acepta authentica notitia de canonica provisione episcopi sive residentiales sive titulares: $1^{\circ}$ Fruuntur privilegio oratorii domestici et altares portatilis ad normam can. 99, De rebus".

${ }^{112}$ Proyecto de libro III, canon 99: "Missae sacrificium omnibus diebus celebrari potest, exceptis iis qui proprio sacerdotis ritus excipuntur".

${ }^{113}$ Proyecto de libro III, canon 101: "\$ $\$$. Missa celebranda est super altare consecratum et in ecclesia vel oratorio, ad normam can. 438-481. $\$ 2$. Privilegium ubique celebrando, honesto tamen ac decenti loco et super petram sacram, idest privilegium 'altaris portatilis', ab una Sede Apostolica conceditur. $\$ 3$. Loci Ordinarius aut, si agatur de domo religiosa exempta, Superior mayor, licentiam celebrando extra ecclesiam ac oratorium concedere potest iusta tantum ac rationabili de causa, in aliquo extraordinario casu et per modum actus transeuntis. $\$ 4$. Privilegium altares portatilis non secumfert facultatem celebrando in Mari". 
celebrarse sobre altar consagrado y en iglesia u oratorio $(\$ 1)$ disponía que el privilegio de altar portátil correspondía otorgarlo a la Sede Apostólica $(\$ 2)$ pero que dicho privilegio no facultaba para celebrar en el mar $(\$ 4)$. Los cardenales, en cambio, disponían de ese privilegio, empleando las debidas cautelas ${ }^{114}$. A la luz de lo anterior era que los prelados de Concepción y La Serena opinaban que podía extenderse también a los obispos, que ya gozaban del derecho de altar portátil, el privilegio de celebrar Misa también en los navíos.

Esta opinión, formulada en la reunión episcopal y recogida en el acta, no fue incorporada al informe. Pero el código finalmente le dio la razón a los dos prelados chilenos porque el canon $349 \$ 1 \mathrm{n}^{\circ} 1$ otorgó a los obispos varias de las facultades que el canon 239 del mismo Codex otorgaba a los cardenales, una de las cuales, era la de celebrar sobre altar portátil dondequiera que se hallaren $\left(\$ 1 \mathrm{n}^{\circ} 7\right)$ y de celebrar en el mar, empleando las debidas cautelas ( $\left.\$ 1 \mathrm{n}^{\circ} 8\right)$.

b) Dar a conocer a la Santa Sede las dificultades para dar cumplimiento a ciertas disposiciones del decreto 'Ne temere': Fue una sugerencia hecha en la sesión episcopal del 5 de septiembre por el obispo de La Serena, Ramón Ángel Jara, con ocasión del canon $351 \S 2$ del proyecto ${ }^{115}$, canon referido a los libros parroquiales que debía llevar el párroco ${ }^{116}$.

El Concilio de Trento ${ }^{117}$ había establecido después de una larga discusión, que eran necesarias algunas exigencias de forma para la válida celebración del matrimonio, en concreto, que el consentimiento debía intercambiarse por palabras de presente ante un testigo cualificado que lo recibía en nombre de la Iglesia, el párroco de alguna de los dos contrayentes u otro sacerdote con licencia de aquél, y dos testigos comunes. Con esta exigencia se salía al paso de una corruptela que había surgido después que en la Edad Media triunfase el principio del consensualismo en el matrimonio según el cual consensus facit nuptias non concubitus, el consentimiento es el que hace el matrimonio no el concúbito, y que había permitido los llamados matrimonios clandestinos, en los que el intercambio de consentimiento se prestaba por los contrayentes a solas, sin la presencia de ningún testigo, con los evidentes abusos consecuentes ${ }^{118}$. Pero, si bien Trento pudo superar el abuso

${ }^{114}$ Proyecto de libro II, canon 140: " $\$ 1$. Praeter privilegia de quibus in can. 9 De iudiciis, et can. 33 De delictis et poenis, Cardinales facultate gaudent: $\mathrm{n}^{\circ}$ 6: Fruendi altari privilegiato personali cuotidiano et altari portatili, quovis decenti loco, pro eorum prudenti arbitrio, etiam in Mari, servatos debitis cautelis".

${ }^{115}$ Proyecto de libro II, canon 351: "\$2. In libro baptizatorum adnotet quoque si baptizatus matrimonium contraxerit aut ordinationem susceperit, easque semper adnotationes in documenta accepti baptismatis referat" = " $\$ 2$. Anótese en el libro de bautismo si el bautizado contrajo matrimonio o recibió la ordenación, y consignen todas estas anotaciones siempre en los certificados de bautismo".

${ }^{116}$ Liber secundus, De personis; Pars prima, De clericis; Sectio II, De clericis in specie; Titulus VIII, De potestate episcopali iisque qui de eadem participant; Caput IX, De parochis.

${ }^{117}$ Conc. Trid. sess. 24 , cap. 1 de ref. matr.

118 "[...] y considerando [el Concilio] los graves pecados que se originan de los matrimonios clandestinos, principalmente de los de aquellos que permanecen en estado de condenación, pues que, abandonada la primera mujer, con quien contrajeron matrimonio secretamente, se casan con otra en público, viviendo con ésta en perpetuo adulterio". Ibíd. 
de los matrimonios clandestinos, al amparo de sus normas surgió otra corruptela, la de los matrimonios sorpresa. Porque, si bien el Concilio dispuso la presencia obligada del párroco o de un sacerdote delegado por él para que, en nombre de la Iglesia y como testigo cualificado recibiera el consentimiento de los cónyuges, nada dijo acerca de cómo debía prestarse dicho consentimiento, por lo que surgió la práctica desviada de sorprender al párroco desprevenido, de allí el nombre de matrimonio sorpresa, e intercambiar en su presencia el consentimiento sin que éste pudiera impedirlo ${ }^{119}$. A esta nueva corruptela debió responder la Iglesia lo que hizo con el decreto $N e$ temere de san Pío $\mathrm{X}^{120}$, según el cual, para que la intervención del sacerdote se entendiera válida, debía ser una intervención activa, esto es, le correspondía a él preguntar si los contrayentes consentían en matrimonio, de manera que si tan solo se limitaba a escuchar el consentimiento, sin pedirlo, el matrimonio no era válido (art. IV. 3).

El mismo decreto disponía que, una vez celebrado el matrimonio, el pastor o quien tuviese sus funciones, inscribiese de inmediato en el libro de matrimonios los nombres de los cónyuges y de los testigos, el lugar y el día de la celebración y las cosas que correspondiesen según la forma prescrita por el ritual o por el ordinario (art. IX. 1). Junto a lo anterior, el pastor debía dejar nota en el libro de bautismos, que la mujer había contraído matrimonio en tal o cual día en su parroquia; pero si estaba bautizada en otra parte, el pastor, ya directamente ya a través de la curia episcopal, debía dar aviso al párroco del bautismo, de la celebración del matrimonio, a fin de que el matrimonio quedara inscrito en el libro de bautismo (art. IX. 2).

Aunque no queda claro cuáles eran las dificultades con que tropezaban los obispos para dar cumplimiento "a ciertas disposiciones del decreto" ni tampoco se señalaban estas disposiciones, no es difícil entender que se trataba de las normas referidas a la inscripción del matrimonio, especialmente cuando la novia estaba bautizada en una parroquia diferente de aquella en la que contraía nupcias. No era propiamente una observación al proyecto y, por lo mismo, no se incorporó en el informe. En todo caso, las normas del decreto $N e$ temere fueron incorporadas al Codex, cuyo canon 1103 dispuso lo mismo ${ }^{121}$.

${ }^{119}$ Un ejemplo de este tipo de matrimonios, si bien frustrado, puede leerse en la novela de Alejandro Manzini, Los novios, en la que los protagonistas, Renzo y Lucía, labriegos ambos y enamorados, no pueden contraer matrimonio porque el dueño de las tierras a las que pertenecen se lo ha prohibido al párroco, don Abundio, por lo que tratan de sorprenderlo. Lamentablemente para los enamorados, el párroco se dio cuenta y frustró el intento.

${ }^{120}$ Fue promulgado el 2 agosto 1907 y entró en vigencia el 20 mayo 1908. AAS. 4 (1907), p. 525 .

${ }^{121}$ CIC 1917, canon 1103: "\$ 1. Celebrado el matrimonio, el párroco o quien haga sus veces debe inscribir cuanto antes en el libro de matrimonio los nombres de los cónyuges y de los testigos, el lugar y la fecha de la celebración del matrimonio y todo lo demás, según esté mandado en los libros rituales y por el ordinario propio; y esto aun en el caso de que haya asistido al matrimonio otro sacerdote con delegación suya o del ordinario. $\$ 2$. Debe el párroco anotar también en el libro de bautizados, a tenor del canon $470 \$ 2$, que el cónyuge contrajo matrimonio tal día en su parroquia. $Y$ si el cónyuge fue bautizado en otra parte, el párroco del matrimonio debe comunicar al párroco del bautismo, por si mismo o por medio de la Curia episcopal, la celebración del matrimonio, para 
c) Supresión de las elecciones en las órdenes religiosas más antiguas. Según el acta de la sesión episcopal del 5 de septiembre, "tratóse enseguida del canon 387, referente a los regulares, y después de expresarse los inconvenientes que acarrea la exención de los regulares respecto de las ordenaciones, pues sucede que a veces los obispos se ven obligados a ordenar a indignos que los superiores regulares, no siempre bien elegidos, suelen presentar, el Rmo. señor arzobispo indicó que convendría pedir la supresión de las elecciones en las órdenes religiosas más antiguas".

El ministro ordinario de la sagrada ordenación era y es el obispo propio del ordenando. Podía un obispo, sin embargo, ordenar a ordenandos ajenos, pero para ello era preciso que el obispo de origen dirigiera al obispo ordenante letras dimisorias. Tratándose de religiosos, las dimisorias eran enviadas por los superiores regulares, los que debían dirigirlas al obispo de la diócesis en que estaba situado el convento al que pertenecía el religioso que debía ordenarse, salvo que el obispo estuviera ausente o que no hubiese de hacer ordenaciones, en cuyo caso las dimisorias podía enviarlas el superior regular a cualquier obispo católico ${ }^{122}$. La elección de quien recibía el sacramento del orden correspondía a los superiores del religioso que iba a ordenarse, por lo que el obispo destinatario de las dimisorias no intervenía en la selección del futuro ordenado.

El canon $387^{123}$ del proyecto se refería a las elecciones de los superiores religiosos $^{124}$, si bien el canon se refería principalmente a los superiores de monasterios y congregaciones femeninas; no obstante ello, con ocasión de este canon el arzobispo sugería que se suprimiera en las órdenes religiosas más antiguas la elección de los superiores, pues las elecciones mal hechas, recaídas en superiores poco dignos, acarreaba el problema de que estos podían presentar para ser ordenados, religiosos igualmente poco dignos. La sugerencia del arzobispo González no fue incorporada en el informe enviado a Roma y, en todo caso, de haberlo sido, no habría tenido mayor acogida porque el canon 387 del proyecto pasó a ser, con algunas modificaciones, el canon 506 del $\operatorname{Codex}^{125}$. Sin embargo, el parágrafo 1

que éste sea anotado en el libro de bautizados. $\$ 3$. Cuando el matrimonio se celebra a tenor del canon 1098 [peligro de muerte], el sacerdote, si es que ha asistido a él, y en otro caso los testigos, tienen obligación solidaria con los contrayentes de procurar que el matrimonio celebrado se anote cuanto antes en los libros en que está mandado".

${ }^{122}$ Donoso, Justo, cit. (n. 16), II, pp. 118-122.

${ }^{123}$ Proyecto de libro II, canon 387: " $\$ 1$. Superiores deputentur et, quatenus opus fuerit, removeantur ad normam constitutionum. $\$ 2$. In monasteriis monialium comitiis eligendae antistitae praesit per se vel per alium, quin tamen clausuram ingrediatur, Ordinarius loci aut eius delegatus cum duobus sacerdotibus scrutatoribus, si moniales eidem subiectae sint; secus, superior regularis; sed etiam hoc in casu Ordinarius tempestive moneri debet de die et hora electionis, cui potest una cum superiore regulari praeesse. $\$ 3$. In scrutatores ne assumantur ipsarum monialium confessarii ordinarii. \$4. In mulierum congregationibus iuris pontificii electioni antistitae generalis praesideat per se vel per alium Ordinarius loci, in quo electio peragitur, salvis privilegiis ab Apostolica Sede concessis. $\$ 5$. In mulierum congregationibus iuris dioecesani antistica, ex constitutionum iure, a religiosis eligatur; Ordinarius tamen loci, vel ipse vel delegate munere, suffragiis ferendis praeerit; ac peractam electionem confirmare vel rescindere integrum ipsi est pro conscientiae officio".

${ }^{124}$ Liber secundus, De personis; Pars secunda, De religiosis; Titulus X, De religionum regimine; Caput I, De superioribus et de capitulis.

${ }^{125}$ CIC 1917, canon 506: " $\$ 1$. En las religiones de varones, antes de proceder a la elección de 
del canon finalmente aprobado tuvo una nueva redacción que tiene en cuenta el elemento que preocupaba al arzobispo, al introducir el juramento de que darán el voto "a quienes según Dios juzguen que deben ser elegidos".

d) Publicar el código con un índice detallado por materias. Fue la segunda de las cinco indicaciones que hizo el secretario de cámara del arzobispo, Carlos Silva Cotapos, en la sesión episcopal del 5 de septiembre de 1912, según la cual "que no se publique el código sin un indice muy detallado por materias, para facilitar su estudio y evitar los errores en que al principio puedan incurrir los jueces y prelados eclesiásticos" 126 .

Esta propuesta tampoco fue incorporada al informe final, pero ella coincidía con la intención de los codificadores. En efecto, la edición oficial del código, para su mejor uso, incluía un Index Analytico-alphabeticus elaborado por el cardenal Gasparri además del Index voluminis.

e) Añadir un anexo con las constituciones pontificias que queden vigentes. Fue la tercera de las cinco propuestas de Carlos Silva Cotapos, según la cual "que al código se le añada un anexo que contenga todas las constituciones pontificias a que se alude en los cánones y que queden vigentes" ${ }^{127}$. Tampoco se incluyó en el informe enviado a Roma, pero nuevamente la propuesta del secretario de cámara del arzobispo coincidía con el sentir de los codificadores, pues, en la primera edición del Codex hecha en 1917, después los 2414 cánones que lo integraban, se incluyó una serie de ocho Documenta, algunos referidos a la elección del romano pontífice y otros que eran mencionados en algunos cánones del nuevo código: i) Constitución Vacante Sede Apostolica, de Pío X, de 25 de diciembre de 1904, sobre el gobierno de la Iglesia después de fallecido un papa y el procedimiento para la elección de su sucesor, mencionada en el canon 160; ii) Constitución Commissum Nobis, de Pío X, de 20 de enero de 1904, imponiendo excomunión latae sententiae reservada al futuro pontífice a quienes interpusieran veto contra algún cardenal en cónclave; iii) Constitución Praedecesores Nostri, de León XIII, de 24 de mayo de 1882, sobre elección del romano pontífice; iv) Constitución Cum illud, de Benedicto XIV, de 14 de diciembre de 1742, que reglamenta los concursos especiales a parroquias reglados en el canon $459 \$ 4 \mathrm{del}$ código, en el que se hace expresa referencia a esta constitución; v) Constitución Sacramentum poenitentiae, de Benedicto XIV, de 1 de junio de 1741, sobre el

Superiores mayores, todos y cada uno de los capitulares deben prometer con juramento que darán el voto a quienes según Dios juzguen que deben ser elegidos. $\$ 2$. En los monasterios de monjas presidirá los comicios para la elección de superiora, pero sin entrar en clausura, el ordinario del lugar o un delegado suyo con dos sacerdotes escrutadores, si las monjas están sujetas a dicho ordinario; pero de no ser así, presidirá el superior regular; mas aun en este caso, el día y hora en que se celebrará la elección deben comunicarse con tiempo al ordinario, el cual puede personalmente o por medio de otro asistir junto con el superior regular y, si asiste, presidir la elección. \$3. No deben de hacer de escrutadores los confesores ordinarios de las mismas monjas. $\$ 4$. En las congregaciones de mujeres, la elección de superiora general será presidida, personalmente o valiéndose de otro, por el ordinario del lugar donde aquélla se celebra; el cual, tratándose de congregaciones de derecho diocesano, puede confirmar o rescindir la elección, según le dicte su conciencia.

${ }^{126}$ Retamal Fuentes, Fernando, cit. (n. 18), vol. II, tomo III, p. 1265.

${ }^{127}$ Ibíd. 
delito de solicitación en confesión, mencionada en el canon 904; vi) una parte de la Constitución Altitudo, de Paulo III, de 1 de junio de 1537, sobre la situación de los matrimonios polígamos, o con parientes, de los indios americanos y de lo que hay que hacer para recibir el bautismo, mencionada en el canon 1125; vii) Constitución Romani Pontificis, de san Pío V, de 2 de agosto de 1571, complementando la anterior, mencionada en el mismo canon 1125; viii) Constitución Populis, de Gregorio XIII, de 25 de enero de 1585, sobre el matrimonio de los esclavos bautizados, mencionada también en el mismo canon 1125 .

Sin perjuicio de lo anterior, por circular de 6 de abril de 1904 atribuible al secretario de la Comisión, Pedro Gasparri, dirigida a los rectores de las universidades católicas para pedirles el concurso "en esta empresa importante y difícil" 128 , se afirmaba la intención del papa de "distribuir metódicamente todo el derecho canónico en cánones o artículos, a la manera de los códigos modernos y, al mismo tiempo, de hacer una recopilación de todos los documentos aparecidos después de las colecciones auténticas del Corpus Iuris de las que dichos cánones o artículos deberán ser tomados". En el reglamento de la comisión se dispuso que en la compilación de los cánones o artículos los consultores debían conservar, en la medida de lo posible, las palabras de los documentos de las que eran extraídas, las que debían ir entre comillas (“-”), cuidando al mismo tiempo la brevedad y la claridad, indicando en cada caso la página, el volumen y la edición del documento del cual eran extraídas (art. 8); y que uno o más consultores nombrados por el secretario tendrían el encargo de anotar los documentos de los cuales eran extraídos dichos cánones o artículos, con excepción de los que provenían del Corpus Iuris Canonici o del Concilio de Trento (art. 9). En estas disposiciones se encuentra el punto de partida de lo que, años después, serían los nueve gruesos volúmenes que, publicados en forma privada por Gasparri con la colaboración de Seredi, constituyeron la colección de fuentes del código de 1917, en la que se incluía el texto completo de las fuentes que aparecían indicadas en la edición anotada del Código de Derecho Canónico publicada por la editorial vaticana en 1918. Estas fuentes, sin embargo, no formaron parte oficial del código, conservando el cardenal Gasparri la propiedad intelectual de ese trabajo así como el del índice analítico-alfabético ${ }^{129}$.

${ }^{128}$ Circular Perlegisti, en ASS. 37 (1904-1905), pp. 130-131.

${ }^{129}$ Gasparri, card. Petrus (cura), Codicis Iuris Canonici Fontes, I: Concilia generalia; Romani Pontifices usque ad annum 1745 (Romae, Typis Poliglottis Vaticanis, 1947); II: Romani Pontifices A. 1746-1865 (Romae, Typis Poliglottis Vaticanis, 1948); III: Romani Pontifices A. 1867-1917 (Romae, Typis Poliglottis Vaticanis, 1933); IV: Curia Romana, S.C.S. Off., S. C.. Ep. et Reg. (Romae, Typis Poliglottis Vaticanis, 1941); V: Curia Romana, S. C. Consit., S. C. de Sacramentis, S. C. C. A. 1573-1760 (Romae, Typis Poliglottis Vaticanis, 1941); VI: Curia Romana, S. C. Concilii, an. 1761-1917, S. C. Super Statu Regul., S. C. de Religiosis (Romae, Typis Poliglottis Vaticanis, 1962); VII: Curia Romana, S. C. de Propaganda Fide, S. C. Indulg., S. C. Indicis, S. R. C., an. 1588-1790 (Romae, Typis Poliglottis Vaticanis, 1955); VIII: SEREDI card. Iustiniani (cura et studio), Curia Romana, S. R. C., an. 1804-1917; SS. CC., Caerem. Neg. Eccl. Extr., Stud. Semen., Poenit. Ap., Secr. Stat., Secre. Brev., Reg. Curiae Rom., Vicar. Urb. (Romae, Typis Poliglottis Vaticanis, 1938); IX: Tabellae (Romae, Typis Poliglottis Vaticanis, 1939). 


\section{Resolución tomada por los obispos a partir de la lectura del proyecto de libros I y II.}

La lectura del proyecto de los libros I y II del futuro Código de Derecho Canónico suscitó algunos otros comentarios que, sin ser observaciones al mismo y partiendo de la aceptación de sus normas, permitieron a los prelados chilenos tomar alguna decisión que, en la práctica, suponía poner en práctica por adelantado alguna de sus normas que, al menos de momento, era sólo un proyecto. Esta resolución dijo relación con la provisión a futuro de una canonjía teologal y otra penitenciaria en las diócesis sufragáneas. Según el acta de la reunión episcopal de septiembre de 1912: "respecto del canon 275 del citado libro [libro II], observó el mismo señor obispo [Ramón Ángel Jara, obispo de La Serena] que en las diócesis sufragáneas faltan las canonjías de oficio que, por disposición del Tridentino, deben existir en todas las catedrales. Los señores obispos estuvieron de acuerdo en que, apenas se contase con la aquiescencia del poder civil, deberían dejar de proveerse las canonjias de merced y sustituirlas por la teologal y la penitenciaria".

El canon 275 del libro II del proyecto ${ }^{130}$ a que hacía alusión el obispo serenense, estaba situado entre los cánones relativos a los cabildos de canónigos ${ }^{131}$ y disponía que en ninguna iglesia catedral debía faltar el oficio de canónigo lectoral y canónigo penitenciario $(\$ 1)$.

Ambas canonjías habían sido instituidas por el Concilio IV de Letrán (1215), y confirmadas por el Concilio de Trento (1545-1563) ${ }^{132}$, debiendo recaer el nombramiento de la canonjía lectoral, también conocida como teologal, en un doctor en teología, correspondiéndole dar a los clérigos lecciones de escritura o de teología. El canónigo penitenciario, a quien correspondía oír las confesiones en la iglesia catedral, debía tener 40 años de edad y ser doctor en teología o en derecho canónico. Con todo, las circunstancias del lugar y la necesidad o utilidad de la iglesia permitían la dispensa de estas exigencias. Ambas canonjías formaban parte de los diez canonicatos de erección en las catedrales de América, y eran denominados "de oficio" porque, a más de las obligaciones comunes a todos los canónigos en orden a la celebración de los oficios divinos, el coro y el altar, tenían anexo un oficio especial. A ellas se accedía por oposición ${ }^{133}$.

La decisión de los obispos chilenos fue oportuna, porque el canon 275 del

${ }^{130}$ Proyecto de libro II, canon 275: "\$ 1 . In nulla ecclesia cathedrali desit officium canonici theologi et canonici poenitentiarii. $\$ 2$. Etiam in collegialibus, praesertim insignibus, officium canonici theologi et poenitentiarii constitui potest. \$3. Si in Capitulo cathedrali praebenda pro his officiis deputata non fuerit, episcopus praebendam primo in eodem Capitulo vacaturam ad eum usum perpetuo constituat ac deputet" = "\$1. En ninguna iglesia catedral debe faltar el oficio de canónigo lectoral y el de canónigo penitenciario. \$2. También en las colegiatas, sobre todo en las insignes, puede instituirse el oficio de lectoral y el de penitenciario. $\$ 3$. Si en el capitulo catedral las prebendas no estuvieran establecidas entre los oficios, el obispo constituirá a su uso perpetuo la primera prebenda que vacare en el Cabildo".

${ }^{131}$ Liber secundus, De personis; Pars prima, De clericis; Sectio II, De clericis in specie; Titulus VIII, De potestate episcopali iisque que de eadem participant; Caput V, De capitulis canonicorum.

${ }^{132}$ Conc. Trid., sess. 5 , cap. 1 de ref.; sess. 24, cap. 8 de ref.

${ }^{133}$ Donoso, Justo, cit. (n. 16), pp. 231-232. 
proyecto se transformó en el canon $398^{134}$ del Codex, según cuyo parágrafo 1, en ninguna catedral debía faltar el oficio de canónigo lectoral y, donde fuese posible, el de penitenciario. Según los obispos chilenos, sin embargo, se precisaba "la aquiescencia del poder civil" puesto que el régimen de patronato establecido por la Constitución de 1833 vigente entonces ${ }^{135}$, disponía que era atribución del presidente de la república presentar para las dignidades y prebendas de las iglesias catedrales, a propuesta en terna del Consejo de Estado. De allí la decisión episcopal de que "apenas se contase con la aquiescencia del poder civil", se dejaría de proveer las canonjías de merced para sustituirlas por la teologal y la penitenciaria.

\section{EL "CODEX IURIS CANONICI"}

El 1 de abril de 1913, se envió el Libro tercero, De rebus ${ }^{136}$, anunciándose el envío del Libro cuarto, De delictis et poenis ${ }^{137}$, y del Libro quinto, De iudicis ecclesiasticis $^{138}$, que les serían transmitidos, respectivamente, el 1 de julio de 1913 y el 15 de noviembre de 1914. No he encontrado observaciones de los obispos de la provincia eclesiástica chilena al libro III sobre las cosas, pero sí las hay respecto de los otros dos, las que, por falta de espacio, he de abordar en otro momento.

Hacia junio de 1914 se trabajaba en el proyecto de constitución con la cual el papa podría haber promulgado el código en los primeros días de 1915. Sin embargo, el estallido de la primera Guerra Mundial y la muerte de Pío X (20 agosto 1914) retrasaron en un par de años la promulgación del Codex. A Pío X le sucedió en el trono pontificio Benedicto XV (1914-1922) quien, desde su elevación al pontificado había manifestado su decisión de terminar la tarea iniciada por su predecesor. El aplazamiento del proyecto, no obstante que el trabajo ya estaba terminado, hizo que el nuevo papa, como ya lo había hecho su antecesor, promulgara algunos decretos que parecen anticipos del código que estaba pronto a terminar.

El 27 de mayo de 1917, festividad de Pentecostés, el papa Benedicto XV, mediante la constitución apostólica Providentísima mater Ecclesia promulgó el Código de Derecho Canónico ${ }^{139}$. La edición oficial del código se hizo el 28 de

${ }^{134}$ CIC 1917, canon 398: "\$ 1. En ninguna catedral debe faltar el oficio de canónigo lectoral, $y$, donde sea posible, el de penitenciario. $\$ 2$. También en las colegiatas, sobre todo en las insignes, puede instituirse el oficio de lectoral y el de penitenciario".

${ }^{135}$ Constitución de 1833, artículos 82 n 8, $102 \mathrm{n}^{\circ} 3$.

${ }^{136}$ (Schema Codicis Iuris Canonici)/ (Sub secreto pontificio)/ Sanctissimi Domini Nostril Pii PP. X/ Codex Iuris Canonicil cum notis/ Petri card. Gasparril [escudo pontificio de Pío X]/ Romael Typis polyglottis Vaticanis/ MDCCCCXIII/, 365. pp., y 831 cánones. ASV. CIC 1917, caja 51.

${ }^{137}$ (Schema Codicis Iuris Canonici)/ (Sub secreto pontificio)/ Sanctissimi Domini Nostril Pii PP. X/ Codex Iuris Canonicil cum notis/ Petri card. Gasparril [escudo pontificio de Pío X]/ Romael Typis polyglottis Vaticanis/ MDCCCCXIII/, 106 pp., y 227 cánones. ASV. CIC 1917, caja 79.

${ }^{138}$ (Schema Codicis Iuris Canonici)/(Sub secreto pontificio)/Codex Iuris Canonici/cum notis/ Petri card. Gasparri/ [escudo pontificio de Benedicto XV]/ Romae/ Typis polyglottis Vaticanis/ MDCCCCXIV/, 238 pp., y 773 cánones. ASV. CIC 1917, caja 70.

${ }^{139}$ Su texto en $A A S .9$ (1917), pp. 5-8; también en OcHOA, Xaverius (ed.), Leges Ecclesiae 
junio de 1917 en los Acta Apostolicae Sedis, con el título: Codex Iuris Canonici Pii X Pontificis Maximi iussu digestus Benedicti Papae XV auctoritate promulgatus. Con el mismo título se hizo una primera edición el mismo año 1917 de 582 páginas.

Concluida la tarea codificadora, el fondo documental originado con ocasión de la misma, y que estaba previsto en el reglamento de la comisión codificadora, permaneció por años en el archivo de la Secretaría de Estado proveniente de la Sagrada Congregación para los asuntos eclesiásticos extraordinarios, que llegó a ser, con el tiempo, la Sección segunda de la Secretaría de Estado, dicasterio del que dependió la comisión codificadora cuando fue creada en 1904. Cuando, en 1963, se inició la revisión del Código de Derecho Canónico de 1917, tarea que dio origen al Código de Derecho Canónico de 1983 en actual vigencia, aquel rico material fue transferido a la Pontificia comisión para la revisión del Código de Derecho Canónico, para que pudiera ser utilizado por ésta. Finalizado, a su vez, el trabajo de codificación del Codex de 1983, el fondo documental del Código de 1917 fue enviado al Archivo Secreto Vaticano, integrado por 98 legajos ${ }^{140}$.

Por decisión de Juan Pablo II, el año $1985^{141}$ fue autorizada la consulta de los fondos guardados en el Archivo Secreto Vaticano hasta la conclusión del pontificado de Benedicto XV (1922), decisión que ha permitido acceder a los fondos referidos a la codificación del derecho canónico de 1917 y, por lo mismo conocer la intervención que en ella le cupo a los obispos chilenos ${ }^{142}$. Dichos fondos han de complementarse con el Fondo Doppioni, relativo a la codificación de 1917, consistente en 33 legajos; y con el llamado Fondo CIC-Roberti, también referido a la misma codificación y que consiste en ocho carpetas de documentos diversos. Estos dos últimos se encuentran igualmente en el Archivo Secreto Vaticano.

\section{CONCLUSIONES}

Llegados al final de estas páginas, en las que he revisado las observaciones que los obispos de la provincia eclesiástica chilena hicieron en septiembre de $1912 \mathrm{al}$ proyecto de los libros I y II del Código de Derecho Canónico que estaba preparándose en Roma, podemos sintetizarlas en las siguientes conclusiones.

a) El proyecto lo conocieron y lo informaron los obispos residenciales que había en esos momentos en Chile, en concreto, el arzobispo de Santiago, Juan Ignacio González Eyzaguirre, y los obispos de La Serena, Ramón Ángel Jara Ruz; de Concepción, Luis Enrique Izquierdo Vargas; y de Ancud, fray Pedro Armengol Valenzuela Poblete, o. de m., pues todas las diócesis estaban provistas de su propio obispo.

b) Según las instrucciones llegadas desde Roma, además de los obispos residenciales, podía consultarse a los vicarios y prefectos apostólicos, de los que había

post Codicem iuris canonici editae (Roma, 1966), I, p. 60.

${ }^{140}$ Llobell, Joaquín; De León, Enrique; Navarrete, Jesús, cit. (n. 2), pp. 1-3.

${ }^{141}$ AAS. 78 (1986), p. 378.

${ }^{142}$ Archivo Secreto Vaticano, Commissione (Pontificia) per la codificazione del Diritto Canonico, Índice 1164. Se puede consultar Archivo Secreto Vaticano, Indice de los Fondos y relativos instrumentos de descripción de investigación (Ciudad del Vaticano, 2008-2009). 
en Chile al menos dos vicarios apostólicos que eran obispos consagrados apenas algunos meses antes de la consulta romana, el de Antofagasta, Luis Silva Lezaeta, y el de Tarapacá, José María Caro Rodríguez. Sin embargo, sólo participaron el arzobispo y sus obispos sufragáneos por lo que el informe enviado a Roma en 1912 con las observaciones a los libros I y II fue firmado sólo por el arzobispo y sus sufragáneos.

c) De los obispos que participaron en el informe, dos de ellos ya habían participado en el proceso de codificación que se llevaba adelante desde 1904. Uno de ellos era el obispo de Ancud, fray Pedro Armengol Valenzuela Poblete, quien había sido incluido en la primera lista de consultores elaborada en dicho año al inicio mismo de la codificación canónica, mientras se desempeñaba en Roma como maestro general de la Orden de la Merced. El otro era el obispo de La Serena, Ramón Ángel Jara, quien había participado en 1904 en el primer informe enviado a Roma, cuando entonces era obispo de Ancud, no sólo uniéndose al informe enviado por el arzobispo Mariano Casanova, sino agregando propuestas propias. Los otros dos prelados, el arzobispo de Santiago, Juan Ignacio González Eyzaguirre, y el obispo de Concepción, Luis Enrique Izquierdo Vargas se enfrentaban por primera vez al proceso codificador.

c) Según las instrucciones que se dieron a los obispos, podían proceder al examen de los cánones contenidos en los proyectos valiéndose de tres expertos en derecho canónico, clérigos regulares o seculares, quedando tanto los obispos como los consultores obligados al secreto pontificio. No hay muchos antecedentes sobre quienes pudieron haber asesorado a los obispos chilenos; parece, sin embargo, que el único que asesoró a los obispos fue el presbítero Carlos Silva Cotapos, a la sazón secretario de cámara del arzobispo de Santiago, quien le había encargado estudiar el proyecto de Código Canónico, que formuló cinco indicaciones. Había formado parte de la comisión nombrada por el anterior arzobispo de Santiago, Mariano Casanova, para que, bajo la presidencia del obispo Rafael Fernández Concha, los asesorase en la redacción del primer informe que habían enviado a Roma los obispos chilenos, como respuesta a la primera consulta que se les había hecho, los postulata episcoporum.

e) El informe fue debatido en la sesión trienal que tenían los obispos chilenos en cumplimiento a lo que se había solicitado en el Concilio Plenario para América Latina. A su estudio dedicaron tres sesiones de trabajo, los días 4, 5 y 6 de septiembre de 1912, y de sus deliberaciones se dejó un acta que constituye uno de los escasos documentos existentes en Chile en relación con la codificación canónica.

f) Sin embargo, no hay coincidencia en lo que se dijo en dichas sesiones episcopales y lo que finalmente se informó a Roma. En efecto, si bien parte importante de lo sugerido en dichas sesiones se recogió en el informe enviado a Roma, otras sugerencias, en todo caso las menos, se quedaron sólo en conversaciones, sin ningún eco en el informe. Además, con ocasión del estudio de los proyectos, los obispos pudieron tomar una decisión que, en la práctica, significó adelantar lo que en breve dispondría el código aprobado.

g) La consulta se hizo sobre los proyectos de libros I y II, pero las observaciones 
episcopales se refirieron sólo al libro II y no fueron muchas, sólo nueve sobre un total de 567 cánones.

8. De las nueve observaciones, cuatro son meramente formales, que apuntan a una más depurada presentación externa de los cánones, ya pidiendo una numeración única para todos los cánones del código, ya rectificando alguna remisión mal hecha a algún canon, ya mejorando la redacción de la norma eliminando palabras que estaban de más. Las cinco restantes son observaciones en que los prelados sugieren reformas más sustanciales. Unas y otras, sin embargo, van entremezcladas, pues el orden de las propuestas chilenas sigue el orden de los cánones.

h) De las nueve propuestas hechas por los obispos, cuatro fueron sugeridas por el obispo de Ancud, fray Pedro Armengol Valenzuela Poblete; tres por el secretario Carlos Silva Cotapos, una por el obispo de La Serena, Ramón Ángel Jara Ruz, y una por el obispo de Concepción, Luis Enrique Izquierdo Vargas.

i) Alguna propuesta es un tanto audaz, como la de los años que se requerían para adquirir domicilio que, de diez años indicados en el proyecto, se sugiere reducir a dos años. Se trataba de una propuesta lo suficientemente audaz como para que ni siquiera fuera recogida en el código canónico de 1983.

j) De las sugerencias chilenas, dos se refieren a religiosos, y ambas fueron sugeridas por el único obispo religioso que había en esos años en Chile, el obispo de Ancud, Pedro Armengol Valenzuela Poblete.

k) Algunas de las sugerencias chilenas, tres simplemente formales, la primera, la tercera y la cuarta, y una más sustantiva, la novena, fueron recogidas en el código una vez promulgado, pero no puedo pronunciarme si ello ocurrió por el influjo de los obispos chilenos o no, porque pudo haber otros episcopados con similares propuestas. En el caso de la propuesta de fondo, los obispos sugerían agregar una palabra que, tal como ellos la sugirieron y en el lugar en que ellos proponían, apareció en el texto oficialmente aprobado.

l) Otra sugerencia chilena fue aceptada parcialmente; ello ocurrió con la propuesta octava del informe.

m) Alguna de las propuestas discutidas en la reunión episcopal pero finalmente no incluida, no estaba muy alejadas de la realidad porque coincidieron con lo que estableció el código aprobado, como la de incluir entre los privilegios episcopales el de celebrar Misa en altar portátil incluso en los navíos.

[Recibido el 2 de marzo y aprobado el 4 de junio de 2009] 


\section{ANEXO}

[Informe de los obispos de la provincia eclesiástica chilena sobre el proyecto de libro II, De personis, del Código de Derecho Canónico.

Santiago de Chile, 10 de septiembre de 1912

$$
\text { ASV. CIC 1917, caja 85] }
$$

Sancti Jacobi de Chile, die 10 Septembris 1912. I

Metropolita et Antistites Suffraganei Provinciae Chilensis / ad Emam. Vestram mittunt animadversiones in Juris Canonici / Schema ad eos, sub die 20 Martii vertentis anni, missum, quae / sequuntur. /

I. Optandum est ut omnes Codicis canones succesiva et $\mathrm{u}-/$ na tantum numeratione prosequantur usque in finem, non autem / ab initio cujusque libri. /

II. In libro II, can. VI S I dicatur: vel protracta ad biennium / completum, loco decennium completum $^{143}$.I

III. In can. 23 deleatur syllaba cit $^{144}$. I

$I V$. In can. $84 \$ 2$ mutetur phrasis ad normam canonis $76 / \mathrm{cum}$ hac: ad normam canonis $77^{145} .1$

V. In can. 242 addatur incisum haec vel similia verba con- / tinens: "In regionibus ab Urbe dissitis possunt Episcopi visitare / conventus religiosorum exemptorum ad hoc tantum, ut Sanctam / Sedem doceant in Visitatione ad Limina". /

VI. In can. $247 \$ 2 n^{\circ} 2^{\circ}$, post verba quinquaginta dierum / addatur: et indulgentiam plenariam in assumptione muneris et / post visitationem pastoralem cujusque paroeciae $^{146}$. I

Et ad calcem ejusdem canonis ponantur privilegia Emis. // Cardinalibus concessa in art. $140 \$ 1 \mathrm{n}^{\circ} 7^{\circ}, 8^{\circ}$ et $9^{\circ}$. I

VII. In can 259 S 5, substituatur post quinquennium verbis / post sexennium $147 . /$

VIII. In canone 500 n. 1, loco proprietatem vero acquirit ad / normam can 456 dicatur: proprietatem vero acquirit propriae / ecclesiae vel dioecesi ${ }^{148}$. I

IX. In can. $516 \$ 2$, post verbum reticitam addatur: vel / dissimilatam ${ }^{149}$. I

J.Ignatius Archiepiscopus Sancti Jacobi / + Raymundus Angelus / Ep. Serenensis. / +Aloysius Henricus / Epus. Sam. Conceptionis / Fr. P. Armengandius Episc. Ancudiae/ Ad Emum. Card. / Petrum Gasparri /

\footnotetext{
${ }^{143}$ Subrayado en el original.

${ }^{144}$ Ibíd.

${ }^{145}$ Ibíd.

${ }^{146}$ Ibíd.

${ }^{147}$ Ibíd.

${ }^{148}$ Ibíd.

${ }^{149}$ Ibíd.
} 


\section{BIBLIOGRAFÍA}

Archivio Segreto Vaticano, Commissione (Pontificia) per la codificazione del Diritto Canonico, Índice 1164.

Archivo Secreto Vaticano, Indice de los Fondos y relativos instrumentos de descripción de investigación (Ciudad del Vaticano, 2008-2009).

Cabreros de Anta cmf., Marcelino - Alonso Lobo op., Arturo - Alonso Morán op., Sabino, Comentarios al Código de Derecho Canónico (Madrid, Biblioteca de Autores Cristianos, 1963), I.

Código de Derecho Canónico (1917) (1983).

De Fuenmayor, Amadeo, Comentario al canon 102 del CIC 1983, en Instituto Martín de Azpilcueta, Facultad de Derecho Canónico, Universidad de Navarra, Comentario exegético al Código de Derecho Canónico (Pamplona, Eunsa, 1996), I, pp. 735-736.

Delgado Galindo, Miquel, El domicilio canónico (Pamplona, Eunsa, 2006), pp. $29-48$.

Donoso, Justo, Instituciones de derecho canónico americano (Valparaíso, 1848-1849), 2 vols.

FanTAPPIÈ, Carlo, Glinizi della codificazione pio-benedettina, en Il diritto ecclesiastico 113 (2002), pp. 16-83.

FANTAPPIÈ, Carlo, Chiesa romana e modernità giuridica. L'edificazione del sistema canonistico (1563-1903) (Per la storia del pensiero giuridico moderno (Milano, Giuffrè, 2008), 2 vols.

FigueroA, Virgilio, Diccionario histórico biográfico y bibliográfico de Chile 1800-1928 (Santiago de Chile, 1928).

Lombardía, Pedro, Lecciones de derecho canónico (Madrid, Tecnos, 1984).

Llobell, Joaquín - De LeÓn, Enrique - Navarrete, Jesús, Il libro "De processibus" nella codificazione del 1917. Studi e documenti (Milano, Giuffré, 1999).

Oviedo Cavada, Carlos, Los obispos de Chile (Santiago, Editorial Andrés Bello, 1996).

Pontificia Commissio pro America Latina, Acta et decreta Consilii Plenarii Americae Latinae in urbe celebrati anno Domini MDCCCXCIX (Roma, 1906, ed. facs. Ciudad del Vaticano, Librería Editrice Vaticana, 1999).

PRIETO Del Río, Luis Francisco, Diccionario biográfico del clero secular de Chile 15351918 (Santiago de Chile, 1922).

Retamal Fuentes, Fernando, Chilensia Pontificia. Monumenta Ecclesiae Chilensia (Santiago, Ediciones Universidad Católica de Chile, 2002), vol. II, tomos I y II; (Santiago, Ediciones Universidad Católica de Chile, 2005), vol. II, tomo III.

RufFInI, Francesco, La codificazione del diritto ecclesiastico, en AA. VV., Studi di diritto in onore di Vittorio Scialoja (Milano, 1905), II.

Schema Codicis Iuris Canonici. (Sub secreto pontificio). Sanctissimi Domini Nostri Pii PP. X Codex Iuris Canonici cum notis Petri card. Gasparri (Romae, Typis polyglottis Vaticanis, MDCCCCXII). ASV. CIC 1917, caja 23.

SAlinas ARANEDA, Carlos, El primer aporte de los obispos chilenos a la codificación del derecho canónico de 1917: los "postulata" del obispo de Ancud, Ramón Ángel Jara Ruz, en Boletín de la Academia Chilena de la Historia 117 (2008). 
Salinas Araneda, Carlos, El primer aporte de los obispos chilenos a la codificación del derecho canónico de 1917: los "postulata episcoporum" acerca del matrimonio, en Historia 41 (2008) 2.

Salinas Araneda, Carlos, El primer aporte de los obispos chilenos a la codificación del derecho canónico de 1917: los "postulata" del obispo de Concepción, Plácido Labarca, en Revista de Derecho de la Universidad Católica de la Santísima Concepción 17 (2008).

Salinas Araneda, Carlos, Un manuscrito inédito del obispo chileno Rafael Fernández Concha: un proyecto parcial de Código de Derecho Canónico presentado con ocasión de la codificación canónica de 1917, en Revista de Estudios Histórico-Jurídicos 29 (2007).

Salinas ARANeda, Carlos, El primer aporte de los obispos chilenos a la codificación del derecho canónico de 1917: los "postulata episcoporum", en Revista de Estudios Histórico-Jurídicos 30 (2008).

Vetulani, A., Codex Juris Canonici, en Dictionnaire de Droit Canonique (Paris, 1942), III. 
